\title{
Starvation-induced alterations in hepatic lysine metabolism in different families of rainbow trout (Oncorhynchus mykiss)
}

\author{
Angela Higgins \\ West Virginia University
}

Follow this and additional works at: https://researchrepository.wvu.edu/etd

\section{Recommended Citation}

Higgins, Angela, "Starvation-induced alterations in hepatic lysine metabolism in different families of rainbow trout (Oncorhynchus mykiss)" (2004). Graduate Theses, Dissertations, and Problem Reports.

2041.

https://researchrepository.wvu.edu/etd/2041

This Thesis is protected by copyright and/or related rights. It has been brought to you by the The Research Repository @WVU with permission from the rights-holder(s). You are free to use this Thesis in any way that is permitted by the copyright and related rights legislation that applies to your use. For other uses you must obtain permission from the rights-holder(s) directly, unless additional rights are indicated by a Creative Commons license in the record and/ or on the work itself. This Thesis has been accepted for inclusion in WVU Graduate Theses, Dissertations, and Problem Reports collection by an authorized administrator of The Research Repository @ WVU. For more information, please contact researchrepository@mail.wvu.edu. 


\title{
Starvation Induced Alterations in Hepatic Lysine Metabolism in Different Families of Rainbow Trout (Oncorhynchus mykiss)
}

\author{
Angela Higgins \\ Thesis submitted to the \\ College of Agriculture, Forestry and Consumer Sciences \\ at West Virginia University \\ in partial fulfillment of the requirements \\ for the degree of \\ Master of Science \\ in \\ Genetics and Developmental Biology \\ Kenneth P. Blemings, Ph.D., Chair \\ Matthew E. Wilson, Ph.D. \\ Caird E. Rexroad III, Ph.D. \\ Daniel G. Panaccione, Ph.D. \\ Department of Animal and Veterinary Sciences \\ Morgantown, West Virginia \\ 2004
}

Keywords: lysine, lysine $\alpha$-ketoglutarate reductase, lysine oxidation, rainbow trout

Copyright 2004 Angela Higgins 


\begin{abstract}
Starvation Induced Alterations in Hepatic Lysine Metabolism in Different Families of Rainbow Trout (Oncorhynchus mykiss)
\end{abstract}

Angela Higgins

This study focused on lysine catabolism by the lysine $\alpha$-ketoglutarate reductase (LKR) pathway in rainbow trout (RBT). Selective breeding based on feed efficiency in 2 strains (A and B) of RBT generated 2 families within each strain. Eight fish from each of the four families were randomly allotted to individual tanks. Fish were fed until satiation for $3 \mathrm{wks}$ at which time four fish within each family were randomly selected for 2 wks of starvation. After the $2 \mathrm{wk}$ starvation, all fish were harvested. Hepatic in-vitro LKR activity and lysine oxidation (LOX) were measured as was LKR mRNA abundance. Strain A exhibited a 55\% reduction in LKR transcripts compared to strain B pooled across both feeding levels $(\mathrm{P}<0.01)$. LKR mRNA was decreased $(\mathrm{P}<0.01)$ in starved versus fed fish. No differences were detected for LKR activity and LOX between fed and starved fish, between strains or between families. LKR transcripts were positively correlated to weight gain $(\mathrm{p}<0.01)$. 


\section{Acknowledgments}

I'd like to thank Dr. Blemings for all his support and votes of confidence through the uncharted territory of real-time PCR and library screening. Thanks to all my committee members, Drs. Wilson, Panaccione and Rexroad for their time and guidance, Dr. Scott Gahr for showing me numerous lab techniques and assisting in my first library screening, Dr. Jeff Silverstein at the National Center for Cool and Coldwater Aquaculture, for collaborating with our lab and answering all my questions about fish genetics, Dr. Jianbo Yao for his excellent suggestions for improving my library construction, Dr. George Seidel for his superb statistical analysis, Juanita Engles for performing the lysine oxidation experiments, my fellow graduate students, Beth Stinefelt and Aaron Keiss, and our work study, Erin Schenck. 


\section{Table of Contents}

Page

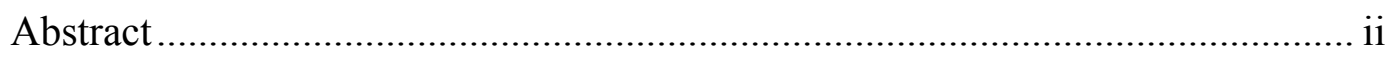

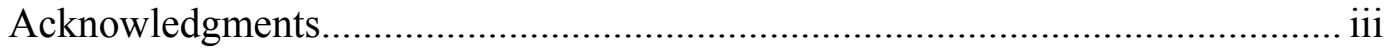

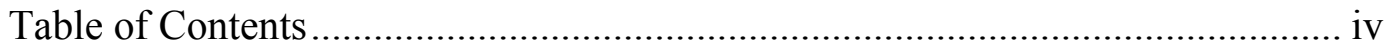

\section{Chapter I. Literature Review}

Lysine and Animal Agriculture ..............................................................

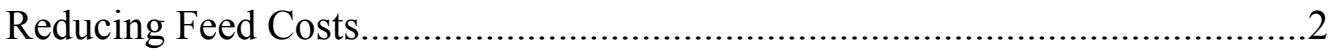

Reducing Nitrogenous Waste ................................................................

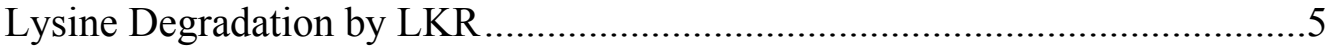

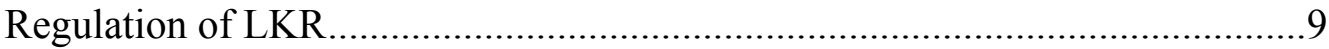

Lysine Degradation in Chickens ............................................................. 13

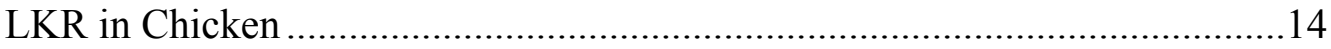

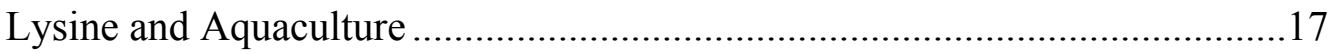

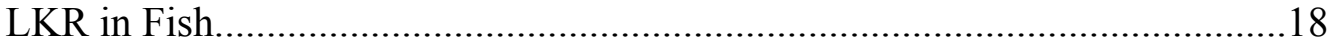

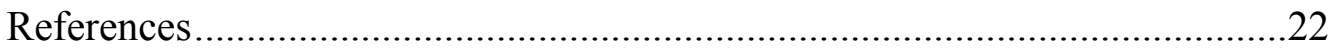

Chapter II. Starvation induced alterations in hepatic lysine metabolism in different families of rainbow trout

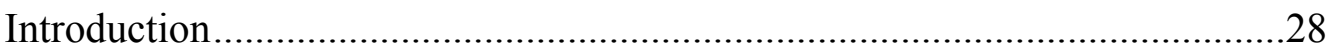

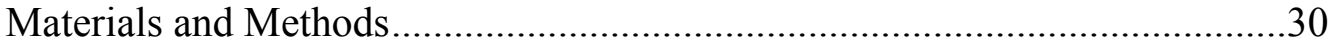

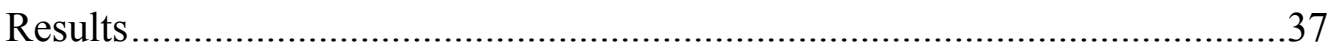

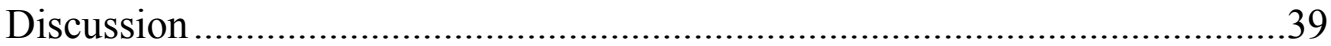


Appendix I: A library screening for chicken lysine $\alpha$-ketoglutarate reductase

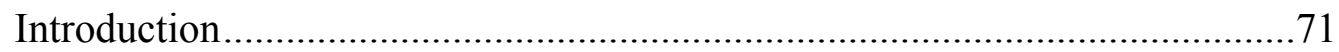

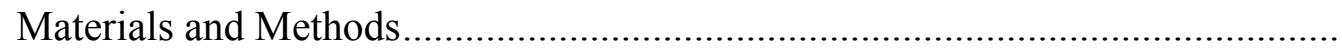

Screening a Chicken Heart Library.................................................... 73

Screening a Chicken Liver Library ...................................................... 77

5' Rapid Amplification of cDNA Ends and Chicken EST Clone...............79

PCR approach for obtaining LKR from library ...................................8

Results

Screening a Chicken Heart Library..................................................... 82

Screening a Chicken Liver Library .....................................................84

5' Rapid Amplification of cDNA Ends and Chicken EST Clone.................87

PCR approach for obtaining LKR from library .....................................89

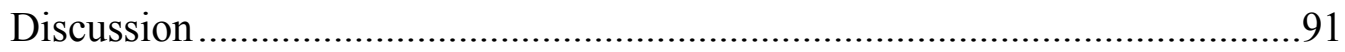

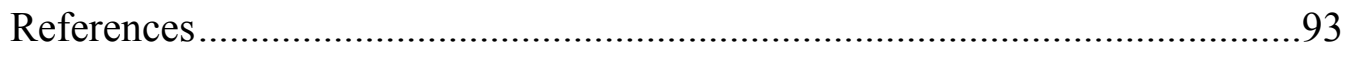




\section{List of Tables and Figures}

\section{Chapter I.}

Figure 1. Initial Enzymatic Reactions in LKR Pathway.........................21

\section{Chapter II.}

Table 1: Strains and Families .........................................................45

Table 2: Composition of Feed ...............................................................46

Table 3: Primer Sequences and PCR Efficiencies ...................................4

Table 4: Inter-Assay and Intra-Assay Variation .....................................48

Table 5: Feed Conversion Ratios ......................................................49

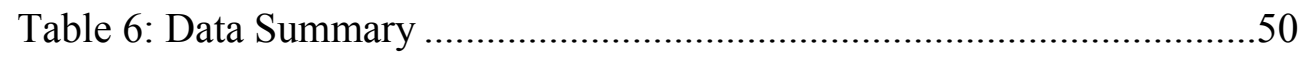

Equation 1: Determination of LKR activity.........................................51

Equation 2: Efficiency Corrected Relative Expression .............................52

Figure 1: Initial Enzymatic Reactions in LKR Pathway.............................53

Figure 2a: Amplification Plot for LKR ..............................................54

Figure 2b: Amplification Plot for ARP ...............................................55

Figure 3a: Melt Curve for LKR ........................................................56

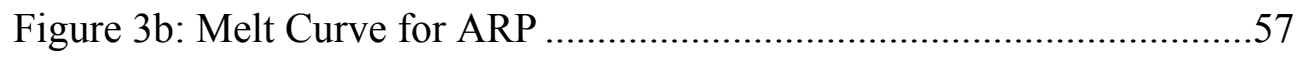

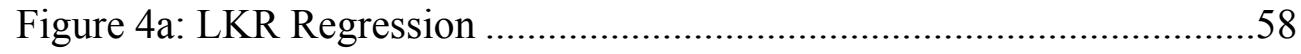

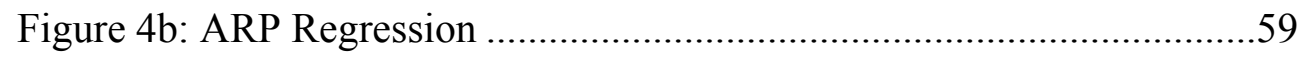

Figure 5: Weight Gained..............................................................6

Figure 6: Relative Liver Size ..........................................................61

Figure 7: Hepatic Lysine Oxidation per gram of liver.............................62

Figure 8: Hepatic Lysine Oxidation per liver ..........................................63 
Figure 9: LKR Activity per gram of liver .............................................64

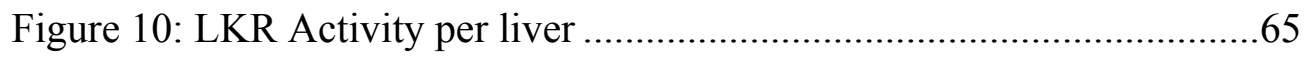

Figure 11. Proportion of LKR mRNA to ARP mRNA..............................66 


\section{Chapter I. Literature Review}

\section{Lysine and Animal Agriculture}

In animal agriculture, much research has focused on determining the dietary requirements for amino acids, specifically essential amino acids (EAA). Essential amino acids must be supplied in the diet because the animal either lacks the ability to make the amino acid or can not synthesize enough to allow for maximum growth. Lysine is an essential amino acid for pigs, chickens, fish and humans.

For animals consuming a corn-soybean based meal diet, lysine can be a limiting amino acid. A limiting amino acid is the dietary amino acid in shortest supply relative to an animal's requirement. Swine diets are typically first limiting in lysine. For poultry and fish diets, methionine is typically the first limiting amino acid, followed by lysine. Lysine deficient diets can limit protein deposition and growth. Therefore, many agricultural industries supplement or formulate diets to meet lysine, as well as, all amino acids requirements.

Lysine used for protein synthesis comes from the free lysine pool. Within an organism, most amino acids exist as residues within a protein. However, amino acids not bound in protein make up the free amino acid pool. Free amino acids are provided by diet and protein turnover, with the latter contributing more. In rats, $70-80 \%$ of tissue amino acid pools are provided by protein turnover (Millward et al., 1976). Increasing the free pool of lysine will increase the amount of lysine available for growth and protein synthesis when diets are lysine limited. The free lysine pool can be increased in two ways 1) providing lysine in the diet and 2) limiting the degradation of free lysine. Limiting lysine degradation is a novel approach to increase the free pool of lysine that 
offers several other advantages over the current practice of diet supplementation/formulation.

First, in most animal agriculture operations, feed represents over half of the variable production costs. Supplementing feedstuffs with lysine or lysine rich soybean meal is relatively expensive compared to other feed ingredients. Decreasing lysine degradation in animals will make cheaper, lysine poor protein sources attractive for diet formulation. Second, feed costs can vary according to the market prices of lysine and soybeans (feedstuffs). Thus, a farmer's profit becomes susceptible to market fluctuations and potential price fixing by these suppliers. Third, decreasing lysine degradation can improve nitrogen retention and reduce the amount of nitrogen in animal waste, thus lessening the impact of agriculture to the surrounding environment. Therefore, strategies aimed at decreasing lysine degradation in animal agriculture can not only improve lysine utilization for protein synthesis but, more importantly offers the potential to reduce feed costs to farmers and decrease the amount of nitrogenous waste entering the ecosystem.

\section{$\underline{\text { Reducing Feed Costs }}$}

Feed accounts for approximately $75 \%$ of total poultry production costs. Poultry are generally fed a corn-soybean meal diet. Corn is inexpensive but a poor quality protein source. Soybean meal must be added to compliment the amino acid profile of corn. Typically, soybean meal is more expensive relative to corn and increases the cost of feed. The lysine content of other protein sources can limit their use in feedstuffs. For example, corn-gluten meal is less expensive than soybean meal, rich in methionine but a very poor source for lysine. Therefore, a better understanding of lysine degradation may 
lead to strategies that prevent the loss of free lysine, thus alternative and cheaper protein sources could be used in chicken feed.

Most producers allow chickens ad libitum access to feed. In this scenario, chickens are likely consuming excess nutrients. Amino acids consumed over their respective dietary requirement are degraded. Degrading excess amino acids is costly to the producer and the environment. First, the chickens will grow less efficiently because energy will be directed away from growth and used to eliminate the excess nitrogen. Second, the producer must realize the cost of inefficient growth. Third, the nitrogen content of chicken waste will increase. Therefore, chickens using amino acids more efficiently will have many benefits to poultry producers.

\section{Reducing Nitrogenous Waste}

For amino acid degradation, the carbon skeleton can have many fates (gluconeogenesis, ketogenesis, energy and lipogensis), while the amino group is converted to ammonia that must be eliminated. The form of nitrogenous waste depends on the animal. Mammals, in general, excrete urea, avian species excrete uric acid, while fish excrete ammonia. In large scale animal agriculture, excess nitrogenous waste can pollute the surrounding ecosystems and ground water.

Broiler chickens produce more manure (lbs. per day/1000 lb. animal unit) containing more nitrogen and phosphorus than any other livestock animal (USDA, National Resources Conservation Service (NRCS), 1995). Disposal of waste has become cumbersome for producers, especially as agriculture becomes more concentrated. Moreover, the EPA reports agriculture is the leading source of water quality impairment 
to rivers and lakes. Excess nutrients from animal waste, if not properly contained, can enter into surrounding lakes and streams. Eutrophication (nutrient enrichment) can reduce the oxygen content and lead to uncontrollable growth of algae and harmful bacteria, thus threatening wildlife and human health.

The social costs of nitrogenous waste disposal from animal agriculture are becoming more visible. In 1997, fish kills, caused by an outbreak of Pfiesteria piscicda, occurred in certain tributaries of Chesapeake Bay. The outbreak of Pfiesteria may of have been linked to nutrient enrichment caused by the poultry facilities surrounding the affected tributaries (Steidinger, K.,1997, Copeland and Zinn, 1998).

One way to reduce the amount of nitrogen that animals excrete is to feed animals the precise amino acid profile needed for optimal growth. Formulating diets that lessen nitrogen excretion is the current strategy for managing nutrient output however, controlling animal intake in large scale agriculture is difficult and timely. Another strategy could be to increase amino acid utilization by decreasing the rate at which limiting amino acids are degraded. Decreasing the rate of lysine degradation from the free pool would increase the amount of lysine available for protein synthesis. Feedstuffs therefore could contain less nitrogen and provide for the same growth rate. 


\section{$\underline{\text { Lysine Degradation by Lysine } \alpha \text {-Ketoglutarate Reductase }}$}

The first step in amino acid degradation is deamination. Amino acids can be deaminated by the direct removal of the amino group or by transfer of the amino group to an acceptor (transamination) which is later deaminated. The assumed predominant pathway for lysine degradation in mammals is the lysine $\alpha$-ketoglutatrate reductase (LKR) pathway. Through this pathway, the lysine epsilon amino group is removed via transamination. The first step of LKR pathway involves the reductive condensation of lysine with $\alpha$-ketoglutarate $(\alpha-K G)$ to form saccharopine by lysine $-\alpha$ - ketoglurate reductase (EC 1.5.1.8; Fig. 1). This was first observed in rat liver mitochondria by Higashino et al. (1965). The second step involves the oxidative cleavage of saccharopine to glutamate and $\alpha$-amino-adipic semialdehyde by saccharopine dehydrogenase (SDH; EC 1.5.1.9). The epsilon amino group is transferred to the $\alpha-\mathrm{KG}$ resulting in a glutamate, which can then be deaminated. In the LKR pathway, several enzymatic steps occur before the lysine carbon is catabolized, with the 1-carbon released prior to the 6-carbon.

Interest in understanding lysine catabolism was generated by familial hyperlysinemia, a condition characterized by hyperlysinemia, lysinuria and variable saccharopiniura (Dancis et al., 1969). Genetic defects in LKR and later SDH (Hutzler and Dancis, 1976) were identified in individuals with familial hyperlysinemia. In babies and young children, hyperlysinemia can cause mental and physical retardation, suggesting a role for lysine in mental development, but this role is poorly understood.

LKR has been found in many species: rats (Higashino et al., 1965; Blemings et al., 1994), mice (Higashino et al., 1971, Papes et al., 1999), cattle (Markovitz et al., 1984; Markovitz et al., 1987), swine (Benevenga et al., 2003, Pink et al., 2002, Blemings, 
1990), chickens (Wang and Nesheim, 1972; Manangi et al, submitted), fish (Walton et al., 1984, Higgins et al., 2004), plants (Karichi et al., 1994, Miron et al., 1997, Epelbaum et al., 1997) and yeast (Jones and Broquist, 1965). Yeast, higher fungi and some green algae use the LKR pathway for lysine biosynthesis.

In yeast, LKR and SDH are encoded on separate genes, LYS1 and LSY9, respectively (Bhattacharjee, 1985). For other higher eukaryotes, evidence exists suggesting LKR and SDH are encoded on one gene which exists as a bifunctional protein usually called $\alpha$ aminoadipic semialdehyde synthase (AASS). In baboon and bovine mitochondria, LKR and SDH enzyme activities copurified together over DEAE-cellulose, Sephacryl S-300 column and a NADP-affinity column (Markovitz et al., 1984). Moreover, LKR/SDH purified protein from bovine and baboon mitochondria showed a $115 \mathrm{kDa}$ band in SDSgel electrophoresis, while gel-filtration on a Sephacryl-300 column indicated the native form to have a molecular weight of $468 \mathrm{kDa}$ (Markovitz et al., 1984), suggesting that LKR and SDH are on one bifuntional protein present as a tetramer. In human liver and placenta, a tetrameric form of AASS has also been reported (Fjellstedt et al., 1975a, 1975b).

Similar to the Markovitz et al. (1984) data in mammals, Goncalves-Butruille et al. (1997) purified a bifunctional LKR/SDH protein from maize. To further support a bifunctional polypeptide, a cDNA encoding AASS was isolated from Arabidopsis thaliana mRNA using 5' and 3' RACE (Epelbaum et al., 1997). The cDNA contained a $3.16 \mathrm{~kb}$ open reading frame (ORF) that predicted both a LKR domain and a SDH domain. The two domains were separated by a 200 amino acid spacer region. A CAAT and TATA box were both identified at -62 and -32 , respectively. The 5' and 3' untranslated 
region (UTR) were 108 and $90 \mathrm{bp}$, respectively. The predicted polypeptide molecular weight was $117 \mathrm{kDa}$. When the cDNA was aligned with the gDNA, the LKR/SDH gene contained 23 introns between 78 and $203 \mathrm{nt}$ in length.

Papes et al. (1999) identified a 3.3kb clone from a mouse liver cDNA library that encoded a LKR/SDH gene. The predicted polypeptide was 926 residues with an expected molecular mass of $109 \mathrm{kDa}$. The mouse amino acid sequence was similar to the AASS predicted polypeptides identified in other organisms. The mouse AASS exhibited $41.6 \%$ and $44 \%$ similarity to maize and Arabidopsis, respectively. The predicted mouse polypeptide was $62.3 \%$ similar to the Caenorhabditis elegans LKR/SDH bifuntional polypeptide. Moreover, Papes et al. (1999) identified an Nterminal mitochondrial localization sequence with a cleavage site at residue 32 using two separate computational analyses. A mitochondrial localization tag was identified at the $\mathrm{N}$-terminus of the C. elegans polypeptide, as well. In rat liver, LKR/SDH is found exclusively in the mitochondrial matrix (Blemings et al., 1994).

Interestingly, the amino acid spacer region between the LKR and SDH domains for the mouse polypeptide is 90 amino acids in length. This is much smaller than the predicted 200 residues for Arabidopsis. Papes et al. (1999) notes that the spacer region between animals and plants is often quite variable in length and sequence. The spacer region is most likely the area where the four polypeptides join together to form the native LKR/SDH protein, at least in mammals. In maize, the size of the purified LKR/SDH native protein suggests a dimer, rather than tetramer (Goncalves-Butruile et al., 1996). Therefore, the differences in the spacer region may reflect differences in the native protein conformation. 
For some species, evidence exists for a monofuntional SDH, as well as, a bifuntional LKR/SDH. LKR and SDH activities were purified from mouse liver and eluted on a Superdex-200 HR column for determination of molecular mass of the protein (Papes et al., 1999). Two peaks were detected that corresponded to 474 and $73 \mathrm{kDa}$, respectively. The peaks were separated by native gel electrophoresis and tested positive for SDH activity. The $474 \mathrm{kDa}$ peak corresponds to the $468 \mathrm{kDa}$ molecular weight for bovine LKR/SDH reported by Markovitz et al. (1984). Papes et al. suggests the $73 \mathrm{kDa}$ protein represents a monofunctional SDH. Interestingly, molecular mass of the yeast mononfunctional SDH is $73 \mathrm{kDa}$ (Feller et al., 1994). Moreover, a northern blot of different mouse tissue hybridized with an SDH probe revealed two bands at 3.4 and 2.4 $\mathrm{kb}$. The same northern blot hybridized with a LKR probe produced only a single band at $3.4 \mathrm{~kb}$. Thus, mouse may possess both a LKR/SDH bifunctional protein and an SDH monofunctional protein. It is unclear if a separate SDH gene exists in the mouse genome. In Arabidopsis, which possess both a bifunctional LKR/SDH and monofunctional SDH (Tang et al., 1997), both enzymes are produced from a single composite locus (Zhu et al., 2000). In a northern blot of different human tissues, no differences in banding patterns were detected between an LKR probe and an SDH probe (Sacksteder et al., 2000). Thus, a monofunctional SDH may not exist for all species and the advantage of such a monofuntional protein is unclear.

Sacksteder et al. (2000) characterized the human AASS as having a $2.7 \mathrm{~kb}$ ORF, which predicts a 927 amino acid polypeptide. The AASS gene was mapped to the long arm of chromosome 7, spanning an area approximately $68 \mathrm{~kb}$ and containing 24 exons. Interestingly, when Sacksteder et al. (2000) used the full-length human AASS cDNA as a 
northern probe for AASS expression, distinct bands at $9 \mathrm{~kb}, 7 \mathrm{~kb}$ and $3.4 \mathrm{~kb}$ were revealed. The $3.4 \mathrm{~kb}$ band corresponds to estimated length of the AASS cDNA but the $9 \mathrm{~kb}$ and 7 $\mathrm{kb}$ bands are somewhat of an anomaly. Sacksteder et al. suggested the large bands represent incompletely spliced mRNA, which is supported by the presence of AASS EST's in Genbank that contain unspliced introns.

\section{$\underline{\text { Regulation of LKR }}$}

The mechanisms responsible for regulating most AA degrading enzymes are still being defined. Similar to other amino acid degrading enzymes, LKR activity adapts to the amount of protein in the diet. Rats fed increasing amounts of protein show increases in LKR activity (Chu et al., 1976, Muramatsu et al., 1984, Blemings et al., 1998). However, unlike other amino acid degrading enzymes (i.e. theronine dehydratase and histidase) LKR is substrate induced (Chu et al., 1976, Foster et al., 1993). Muramatsu et al. (1984) demonstrated an increase in hepatic LKR activity in rats fed graded levels of lysine. Similar experiments conducted in chickens have also reported increases in LKR activity and lysine oxidation with increasing concentrations of dietary lysine (Wang et al., 1973, Manangi et al., 2000). Papes et al. (1999) reported an increase in LKR activity when mice were injected with lysine. Excess lysine also increases LKR activity in tobacco seeds (Karichi et. al., 1995).

Hepatic LKR activity was significantly lower for rats fed a lysine free diet versus a protein free diet (Chu et al., 1976). In the lysine free diet, lysine is limiting, therefore lysine utilization becomes very efficient. In the protein free diets, methionine is most likely first limiting due to smaller concentrations in tissue pools, thus conserving lysine 
will not affect protein synthesis. LKR activity is not significantly different between rats fed a protein free diet and an adequate protein diet (Chu et al., 1976).

Many amino acid catabolizing enzymes respond differently to low/no protein diets and starvation (Harper, 1965). Under low or no protein conditions, energy needs are met therefore, amino acids are conserved for protein synthesis. During periods of starvation, amino acids are rapidly oxidized for energy and gluconeogensis. However, amino acid (AA) degrading enzymes respond differently to starvation. Mice starved for 24-48 hour show a 52\% increase in LKR activity compared to fed controls (Papes et al., 1999). Glutamine-alanine transaminase and threonine dehydratase increase at least 5 fold during starvation (Schimke, 1962). Thus an increase of 52\% seems relatively small compared to the response seen by other AA degrading enzymes.

LKR activity may be under hormonal control. Shino et al. (1980) induced hepatic LKR activity in rats with glucagon, alloxan and glucocorticoid treatments. Mitochondria isolated thirty minutes after rats received glucagon injections showed 2-fold increases in LKR activity (Scislowksi et al., 1994). Increases in glucagon during starvation may therefore be responsible for increases in LKR activity. Blemings et al. (1996) showed a $35 \%$ decrease in hepatic lysine oxidation and LKR activity for rats treated with recombinant bovine somatotropin (growth hormone). Decreases in methionine and valine oxidation were also observed. Recombinant bovine somatotropin enhances growth primarily by increasing protein accretion. Thus, protein accretion may be facilitated by decreases in amino acid catabolizing enzymes activities.

Many hormones regulate cellular processes by signaling cascades. Calcium often acts as a second messenger activating protein kinases. Karchi et al. (1995) suggested LKR 
activity may be regulated by such a mechanism in tobacco seeds. Injecting tobacco seeds with ionomycin, $\mathrm{Ca}^{2+}$ ionophore which transports calcium specifically through cell membranes, increased LKR activity (Karchi et al.,1995). Whereas, seeds injected with EGTA, a calcium chelator, saw a reduction in LKR activity. Seeds injected with both EGTA and $\mathrm{Ca}^{2+}$ had the same level of LKR activity as the controls.

Karchi et al. (1995) also examined the effect of K-252a (kinase inhibitor) and okadaic acid (phosphatase inhibitor) injections on LKR activity in tobacco seeds. The kinase inhibitor reduced LKR activity, while the phosphatase inhibitor increased LKR activity. Neither response was concentration dependent. Since these were broad inhibitors other cellular processes were most likely effected. Unfortunately, Kachi et al. failed to statistically analyze these data.

More evidence for the phosphorylation dependent activation of LKR was presented by Miron et al. (1997). LKR/SDH activities were copurified from soybean seeds and invitro phosphorylated using casein kinase II and $\gamma_{-}{ }^{32} \mathrm{P}$ ATP. Moreover, purified fractions of LKR/SDH activity treated with alkaline phosphatase showed a concentration dependent decrease in LKR activity. The effects of alkaline phosphatase were overcome when increasing amounts of $\beta$-glycerol phosphate was added. $\beta$-glycerol phosphate is a competitive inhibitor of alkaline phosphatase. The recovery of LKR activity suggests phosphorylation may be important in regulating LKR activity, at least in plants. Moreover, LKR/SDH fractions incubated with alkaline phosphatase and lysine showed $50 \%$ less activity than fractions incubated only with alkaline phosphatase. Thus, binding of lysine to the enzyme may be necessary for phosphatase activity. Miron et al., also failed to statistically analyze these data. 
Changes in gene expression may also mediate changes in LKR activity, similar to other amino acid catabolizing enzymes. For example, rats fed increasing amounts of casein showed a concomitant increase in histidase protein, mRNA and activity (Torres et al., 1998). However, increases in dietary histidine had no affect on histidase activity (Torres et al., 1998). As stated previously, LKR activity does respond to dietary lysine. Increases in LKR mRNA and LKR activity were observed in mice injected with lysine (Papes et al., 1999). Moreover, using northern blot analysis, Papes et al. (1999) reported an $80 \%$ increase in LKR/SDH mRNA in mice starved for $24-48$ hours, accompanied by a $52 \%$ increase in LKR activity. However, in mice fed $20 \%$ or $40 \%$ casein diet, Keiss et al. (2004) reported a 2 -fold increase in LKR activity in the mice fed $40 \%$ casein, while LKR mRNA and LKR protein increased $10 \%$ and $20 \%$, respectively. It is unclear to what extent LKR expression mediates LKR activity. Control of LKR transcription may be only one of many ways for regulating LKR activity. Thus far, no studies in animals have looked at phosphyorlation mechanisms.

Most research regarding mechanisms for LKR regulation has been conducted in plant seeds. The regulation of lysine metabolism in plant seeds has been of particular interest since most cereal grains are limiting in lysine. Plants, in particular the seeds, synthesize lysine from aspartate however, accumulation of lysine is tightly controlled by the catabolic activity of LKR (Karchi et al., 1995). Generating transgenic seeds with lower LKR activity is viewed as a feasible way to increase the lysine concentrations in cereal grains by many. In fact, an Arabidopsis knockout mutant for LKR/SDH has been reported to have slight but significantly more free lysine than wildtype (Zhu et al., 2001). However, increasing the lysine content of cereal grains may not improve an animal's 
nitrogen retention, thus reducing nitrogenous waste in animal agriculture would still need to be addressed. Strategies aimed at down regulating LKR activity in animals would not only improve lysine retention such that more substrate is available for protein synthesis but also reduce nitrogen excretion.

\section{$\underline{\text { Lysine Degradation in Chickens }}$}

Lysine degradation has been studied minimally in chickens. The LKR pathway is assumed to be the primary pathway of lysine degradation in mammals, although this may not be true for avian species. Other enzymes are capable of oxidizing free lysine: lysyl oxidase (Trackman and Kagan, 1979), L-amino acid oxidase (Boulanger and Osteux, 1956, Struck and Sizer, 1960), ornithine trancarbamoylase (Paik et al., 1977) and ornithine decarboxylase (Pegg and McGill, 1979).

Free lysine can serve as a substrate for lysyl oxidase (Trackman and Kagan, 1979, Davis, M, unpublished). Lysyl oxidase post-translationally modifies protein bound lysine residues in connective tissues, like collagen and elastin, to form cross links.

When lysyl oxidase uses frees lysine as a substrate the resulting product is $\alpha$ aminoadipate- $\delta$-semialdehyde, the same product formed from lysine metabolism via the LKR pathway.

Lysine has also been shown to serve as a substrate for enzymes that normally oxidize ornithine. Lysine and ornithine only differ by one methylene group in their side chains, thus a few enzymes have been shown to act on lysine in-vitro. Paik et al. (1977) demonstrated that ornithine transcarbamoylase can use lysine, instead of ornithine, to produce homocitrulline. However, this is unlikely to happen in-vivo since birds lack a 
functional urea cycle. Ornithine decarboxylase can also act on lysine leading to the formation of cadaverine and $\mathrm{CO}_{2}$ in rat tissues (Pegg and McGill, 1979), however this has not been demonstrated in chicken.

In birds, unlike mammals, L-amino acid oxidase uses lysine as a substrate (Boulanger and Osteux, 1956, Struck and Sizer, 1960). Wang and Nesheim (1972) used L-U- ${ }^{14}$ Clysine to demonstrate the presence of both L-amino acid oxidase and LKR activity in

chicken liver homogenate. L-amino acid oxidase could significantly contribute to lysine degradation making lysine degradation in chickens distinguishable from other species.

L-amino acid oxidase, lysyl oxidase and LKR are all capable of degrading lysine in chickens. The total contribution of each enzyme to lysine oxidation is unknown, therefore in terms of whole body lysine oxidation, all possibilities should be considered. More data is necessary to discern the relative contribution of each enzyme to the degradation of free lysine in chickens.

\section{$\underline{\text { LKR in Chicken }}$}

Little data exists for lysine degradation by the LKR pathway in chickens. Overall, the data suggests: (1) LKR activity responds to increases in dietary lysine, similar to other animals; (2) LKR activity and lysine efficiency can vary among genetic strains; and (3) LKR activity in extra-hepatic tissues can significantly contribute to total lysine oxidation.

Wang and Nesheim (1973) evaluated the effect of strain and excess dietary lysine in chickens using two strains of chickens, a high arginine (HA) requiring and low arginine (LA) requiring strain. In general, when fed a basal diet, the LA strain had much higher hepatic LKR activity than the HA strain (1973). The LA strain also degraded 
significantly more $\left[\mathrm{U}_{-}{ }^{14} \mathrm{C}\right] \mathrm{L}$ - lysine in vivo than the HA strain when fed a basal diet. Analysis of variance (ANOVA) indicated an effect of strain for both lysine oxidation and LKR activity.

Both strains significantly increased LKR activity in response to increased dietary lysine. Not surprisingly, the LA strain had a significantly higher hepatic LKR activity compared to the HA strain when fed increasing amounts of dietary lysine. ANOVA showed a significant effect of diet on LKR activity and an interaction between diet and strain. The mechanisms responsible for the differences in lysine degradation were not examined in this study however the data supports genotypic influences over lysine degradation and LKR activity in chickens.

Tesseraud et al. (1999) examined the effects of lysine deficient diets on the carcass quality of two different strains of chickens. The quality line (QL) was much less sensitive $(\mathrm{p}<0.01)$ than the control line $(\mathrm{CL})$ to lysine deficiency. The QL line gained significantly more body weight, breast weight and leg muscle weight on the lysine deficient diets. The authors suggest the QL used lysine more efficiently than the CL line, thus the response to lysine deficiency depended on genotype.

Regulation of protein deposition is poorly understood. Other studies with fat and lean lines of chickens have supported interactions between amino acid utilization and genotype (Leclerq et al.,1994). The previous two studies suggest a relationship between lysine degradation (Wang and Nesheim, 1973) or lysine utilization (Tesseraud et al., 1999) and genotype. The mechanisms controlling lysine degradation are unclear and need to be better characterized before discerning how genotype affects lysine metabolism. 
LKR is extensively expressed throughout different tissues based on RT-PCR analysis (Manangi et al., 2004 submitted). In the same study, hepatic LKR activity and lysine oxidation had the highest activity per gram of tissue of the nine tissues studied. However, when data was expressed per $100 \mathrm{~g}$ of body weight, the intestine had the highest LKR activity, while the muscle oxidized the most lysine. Therefore, it will be important to consider the relative contribution of all tissues when developing strategies to decrease lysine degradation in the chicken.

Lysine metabolism appears to have a genetic component in chickens, which could possibly be exploited in the future to decrease lysine degradation. Specific knowledge of mechanisms regulating lysine degradation will be important for implementing such a strategy. Since LKR may be responsible for most lysine degradation in the chicken, strategies aimed at down regulating LKR activity may increase lysine retention/utilization.

The work described in chapter II, is aimed at obtaining a chicken LKR cDNA clone. Possession of a LKR cDNA clone could provide important information about the regulation of LKR activity. First, sequence analysis could reveal important regulatory regions for transcription or translation. Second, the inferred protein structure could be assessed for phosphorylation and substrate binding sites. Third, the LKR clone could be used to generate antibodies thus, providing a tool for protein studies in the future. Finally, the effects of base pair mutations on transcription, translation and protein function could be examined. 


\section{Lysine and Aquaculture}

Aquaculture is rapidly growing in the United States. The USDA estimates that over a billion dollars worth of aquaculture products were sold in 2002 with approximately 40 million pounds of rainbow trout (RBT) contributing to these sales. As aquaculture expands, research has been aimed at not only reducing the costs of production but also reducing the environmental impact of aquatic agriculture. Lysine is second-limiting next to methionine in fish meal diets. Little is known about lysine metabolism in fish, however, improving lysine utilization in fish would benefit farmers in several ways.

First, carnivorous fish, like RBT, are metabolically equipped to use protein as their primary energy source (Cho et al., 1990, Kim et al., 1991) and require a much higher concentration of dietary protein $(>40 \%)$ relative to other animals in agricultural systems (6-20\%). High protein diets are on average more expensive, thus in aquatic animal culture, feed costs account for approximately $30-70 \%$ of the variable production expense (Shang and Tomasso, 1990).

Second, RBT feeds usually contain fish meal as the primary protein source (Hardy, 1999). However, fish meal production is not increasing and may not meet the future demands of feed producers. Thus, plant protein is quickly replacing fish meal as a protein source in fish feed. Lysine is often first limiting in plant protein sources. Moreover, lysine supplementation of plant based diets has been shown to significantly improve growth performance of RBT (Cheng et al., 2003a). In the future, understanding lysine degradation in rainbow trout may provide insight for improving lysine utilization thus alleviating the need for lysine supplementation to plant based diets. 
Third, nitrogenous waste products are primarily of dietary origin (Gatlin et al., 2002). Amino acids not used for protein accretion are easily catabolized and the nitrogen excreted as ammonia through the gills. Wu (1995) suggested more than half of dietary protein ends up as waste. Some aquaculture systems (i.e. cages, net-pens, raceways) exchange water with the surrounding environment very readily therefore, managing nutrient loss (i.e. nitrogen, phosphorus, uneaten feed) from these systems is more challenging and costly to the producer. Nitrogenous waste is approximately $75-90 \%$ ammonia (Kaushik and Cowey, 1991) suggesting amino acid degradation is responsible for most of the nitrogenous waste.

Many studies have demonstrated significant reductions in total ammonia nitrogen (TAN) excretion by reducing dietary crude protein fed to fish and supplementing with lysine (Viola and Lahav., 1991, Viola et al., 1992., Rodehutscord et al., 1994). Recently, Cheng et al. (2003b) reported a significant decrease of TAN and soluble-phosphorus in fish fed plant based diets supplemented to $1.9-2.25 \%$ lysine compared to diets containing 1.5-1.8\% lysine. Therefore, in lysine limiting diets, improving lysine utilization, will help to limit nitrogenous waste.

\section{$\underline{\text { LKR in Fish }}$}

Much less is known about lysine oxidation in fish compared to other animals. Aquaculture is relatively new to animal agriculture therefore, most research has been focused on determining amino acid requirements. However, understanding amino acid catabolism and its role in protein deposition is becoming a critical area for research. 
Lysine catabolism by the LKR pathway is the presumed major route of lysine degradation in fish, since the LKR pathway is believed to be the predominant pathway for lysine degradation in mammals (Broquist, 1991). Only one report exists for LKR activity in RBT (Walton et al., 1984).

Walton et al. (1984) examined the effects of dietary lysine concentration ranging from $10.4 \mathrm{~g}$ lysine $/ \mathrm{kg}$ feed to $26 \mathrm{~g}$ lysine $/ \mathrm{kg}$ feed in RBT fingerlings fed for 12 weeks. Using the broken line method, Walton estimated the dietary requirement for lysine to be $19 \mathrm{~g}$ lysine $/ \mathrm{kg}$ diet. At the lowest and highest lysine intake, LKR activity was $155 \pm 31$ and $180 \pm 31 \mathrm{nmol}$ lysine degrades/ min*g liver, respectively and not significantly different. However, the statistical power was quite limited in the study of Walton et al. (1984). The experimental unit for each treatment was low (2 tanks). Moreover, only two fish from each tank were used to estimate LKR activity. Another problem with the data arises because LKR activity was measured in mitochondria but expressed per gram of liver. However, the values were not corrected for mitochondrial recovery, which can be highly variable.

Walton et al. (1984) also examined lysine oxidation using [U- $\left.{ }^{14} \mathrm{C}\right]-\mathrm{L}-\mathrm{lysine}$. Lysine oxidation increased 2-fold when the dietary lysine value exceeded $20 \mathrm{~g} / \mathrm{kg}$ diet. The fish fed $10.4 \mathrm{~g} / \mathrm{kg}$ diet oxidized the least amount of lysine, approximately $1 / 3$ of the lysine oxidized by the fish receiving $20 \mathrm{~g} / \mathrm{kg}$ diet. Similar responses to lysine intake have been reported in other animals and reflect a metabolic adaptation to conserve amino acids (Harper, 1965). Increases in LKR activity did parallel increases in lysine oxidation and vice versa. LKR contribution to total lysine oxidation is still unclear. 
Further knowledge of lysine degradation may have significant value in the future to the aquaculture industry. Understanding the basic mechanisms of lysine degradation and specifically LKR activity will enable the development of genetic tools to manipulate lysine degradation. The work described in chapter II investigates the regulation of LKR activity and lysine oxidation. Since starvation and strain have been shown to affect LKR activity in other species, starvation induced alterations in hepatic lysine metabolism were studied in different families of rainbow trout. 
Figure 1. Initial Enzymatic Reactions in LKR pathway

\section{Lysine}

NADPH
$\alpha$-ketoglutarate

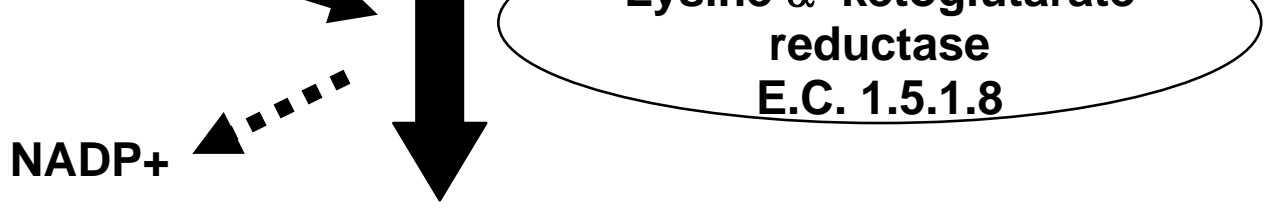

Saccharopine
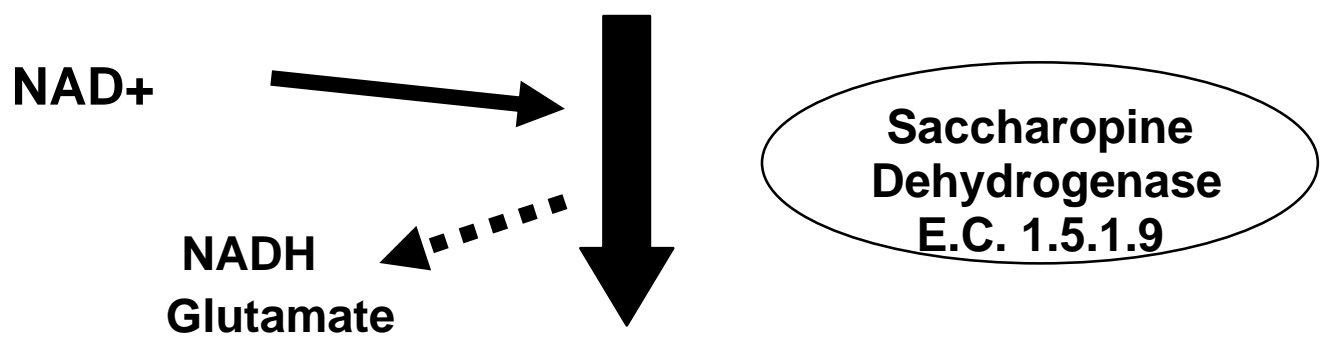

$\alpha$-Aminoadipate- $\gamma$-semidaldehyde 


\section{References}

1. Benevenega, N.J., Haas, L.G., Crenshaw, T.D., 2003. Accepted metabolic pathways do not predict the lack of recovery of free L-lysine in whole body and urine of piglets infused with a 7 fold excess of L-lysine. FASEB J. 17:A734.

2. Bhattacharjee, J.K., 1985. $\alpha$-Aminoadipate pathway for the biosynthesis of lysine in lower eukaryotes. Crit. Rev. Microbiol. 12, 131-151.

3. Blanchard, M., Green, D.E., Nocito, V., Ratner, S., 1944. L-amino acid oxidase of animal tissues. J. Biol. Chem. 155, 421-440.

4. Blemings, K.P., 1990. Lysine metabolism in rats and pigs: 1.subcellular location of lysine- $\alpha$-ketoglutarate reductase in rat and pig liver: 2 . response of mitochondrial lysine metabolism to 5,18 or $60 \%$ casein diets in the rat. MS thesis. University of Wisconsin-Madison.

5. Blemings, K.P., Crenshaw, T.D., Benevenga, N.J., 1994. Lysine $\alpha$-ketoglutarate reductase and saccharopine dehydrogenase are located only in the mitochondrial matrix in rat liver. J. Nutr. 123, 332-336.

6. Blemings, K.P., Crenshaw, T.D., Benevenga, N.J., 1998. Mitochondrial lysine uptake limits lysine oxidation in rats fed diets containing $5,20,60 \%$ casein. J. Nutr. 128, $2427-2434$.

7. Boulanger, P., Osteux, R., 1956. Action de la L-aminoacide-deshdrogenere. du foie de dindon (Meleagris Gallopavo L.) sur les acides amines basiques. Biochim. Biophys. Acta 21, 552-561.

8. Cheng, Z.J., Hardy, R.W., Ursy, J.L., 2003a. Effects of lysine supplementation in plant protein-based diets on the performance of rainbow trout (Oncorhynchus mykiss) and apparent digestibility coefficients of nutrients. Aquaculture 215, 255-265.

9. Cheng, Z.J., Hardy, R.W., Ursy, J.L., 2003b. Plant protein ingredients with lysine supplementation reduce dietary protein level in rainbow trout (Oncorhynchus mykiss) diets, and reduce ammonia nitrogen and soluble phosphorus excretion. Aquaculture $218,553-565$.

10. Cho, C.Y., Kauchik S.J., 1990. Nutritional energetics in fish: energy and protein utilization in rainbow trout (Salmo gairdneri). World Rev. Nutr. Diet. 61, 132-72.

11. Chu, S.W., Hegsted, D.M., 1976. Adaptive response of lysine and threonine degrading enzymes in adult rats. J. Nutr. 106, 1089-1096.

12. Copeland, C., Zinn, J., 1998. Congressional Research Service Report 98-451: Animal Waste Management and the Environment, May 1998. 
13. Dancis, J., Hutzler, J., Cox, R.P., Woody, N.C., 1969. Familial hyperlysinemia with lysine $\alpha$-ketoglutarate reductase insufficiency. J. Clin. Invest. 48, 1447-1452.

14. Epelbaum, S., McDevitt R., Falco, S.C., 1997. Lysine-ketoglutarate reductase and saccharopine dehydrogenase from Arabidopsis thaliana: nucleotide sequence and characterization. Plant Mol. Bio. 35, 735-748.

15. Feller, A., Dubios, E., Ramos, F., Pierard, A., 1994. Repression of the genes for lysine biosynthesis in Saccharomyces cerevisiae is caused by limitation of Lys 14dependent transcriptional activation. Mol. Cell Biol. 14, 6411-6418.

16. Foster, A.R., Scislowski, P.W.D., Harris, I., Fuller, M.F., 1993. Metabolic response of liver lysine $\alpha$-ketoglutarate reductase activity in rats fed lysine limiting or lysine excessive diets. Nutrition Research 13, 1433-1443.

17. Foster, G.D., Moon, T.W., 1991. Hypometabolism with fasting in the yellow perch (Perca flavescens): A study of enzymes, hepatocyte metabolism, and tissue size. Physiol. Zool. 64, 259-275.

18. Gatlin D.M., Hardy, R.W., 2002. Manipulations of diets and feeding to reduce losses of nutrients in intensive aquaculture. In: Tomasso, J.R. (Ed.), Aquaculture and the environement in the United States. World Aquaculture Society, 155-165.

19. Gjedrem T., 2000. Genetic improvement of cold-water fish species. Aquaculture Research 31, 25-33.

20. Goncalves-Butruille, M., Szajner, P., Torigoi, E., Leite, A., Arruda, P., 1996. Purification and characterization of the bifunctional enzyme lysine-ketoglutaratesaccharopine dehydrogenase from maize. Plant Phys. 110, 765-771.

21. Hardy, R.W., 1999. Aquaculture's rapid growth requirements for alternate protein sources. Feed Management 50, 25-28.

22. Harper, A.E., 1965. Effect of variation in protein intake on enzymes of amino acid metabolism. Can. J of Biochem. 43,1589-1603.

23. Higashino, K., Tsukada, K., Lieberman, I., 1965. Saccharopine, A product of lysine breakdown by mammalian liver. Biochem. Biophys. Res. Comm. 20, 285-290.

24. Higashino, K., Fuijioka, M., Yamamura, Y., 1971. The conversion of L-lysine to saccharopine and $\alpha$-aminoadipate in mouse. Arch. Biochem. Biophys. 142:606-614.

25. Higgins, A.D., Silverstein, J.T., Wilson, M.E., Rexroad III, C.E., Blemings, K.P., 2004. The effect of genetics and starvation on lysine catabolism in rainbow trout (Oncorhynchus mykiss) liver. FASEB J. 18:A539. 
26. Hutzler, J., Dancis, J., 1968. Conversion of lysine to saccharopine by human tissues. Biochim. Biophys. Acta. 158, 62-69.

27. Hutzler, J., Dancis, J., 1975. Lysine-ketoglutarate reductase in human tissues. Biochim. Biophys. Acta 377, 42-51.

28. Jones, E.E., Broquist, H.P., 1965. Saccharopine, an intermediate of the aminoadipic acid pathway of lysine catabolism. II. Studies in saccharopmyces cereviseas. J. Biol.Chem. 240, 2531-2536.

29. Karichi, H., Shaul, O., Galili, G., 1994. Lysine synthesis and catabolism are coordinately regulated during tobacco seed development. PNAS 91, 2577-2581.

30. Karichi, H., Miron, D., Ben-Yaacov, S., Galili, G., 1995. The lysine-dependent stimulation of lysine catabolism in tobacco seed requires calcium and protein phosphorylation. Plant Cell 7, 1963-1970.

31. Kaushik, S.J., Cowey, C.B., 1991. Dietary factors affecting nitrogen excretion by fish. In: Cowey, C.B., Cho, C.Y. (Eds.). Nutritional Strategies and aquaculture waste. Proceedings of the First International Symposium on Nutritional Strategies in Management of Aquaculture Wastes. University of Guelph, Ontario, Canadia. Blackwell Publishing, Oxford, UK, 3-19.

32. Kiess, A.S., Stinefelt, B.M., Cantrell, C.M., Higgins, A.D., Wilson, M.E., Klandorf, H., Blemings, K.P., 2004. Regulation of hepatic lysine $\alpha$-ketoglutarate reductase in mice fed high or adequate protein diets. FASEB J. 18:A539.

33. Kim, K.I., Grimshaw, T.W., Kayes, T.B., Clyde, H.A., 1992. Effect of fasting or feeding diets containing different levels of protein or amino acids on the activities of the liver amino acid-degrading enzymes and amino acid oxidation in rainbow trout (Oncorhynchus mykiss). Aquaculture 107, 89-105.

34. Kim, K.I., Kayes, T.B., Amundson, C.H., 1991. Purified diet development and reevaluation of the dietary protein requirement of fingerling rainbow trout (Oncorhynchus mykiss). Aquaculture 96, 57-67.

35. Leclercq, B., Chagneau, A.M., Cochard, T., Khoury, J., 1994. Comparative responses of genetically lean and fat chickens to lysine, arginine and non-essential amino acid supply, I. Growth and body composition. Brit. Poult. Sci. 35, 687-696.

36. Managi, M., Hoewing, S.F.A., Engles, J.G., Higgins, A.D., Killefer, J., Wilson, M.E. and Blemings, K.P., 2004. Lysine $\alpha$-ketoglutarate reductase is widely distributed in the chicken. J.Nutr. (In press). 
37. Markovitz, P.J., Chuang, D.T., Cox, R.P., 1984. Purification and characterization of the bifunctional aminoadipic semialdehyde synthase with lysine-ketoglutarate reductase and saccharopine dehydrogenase activities. J. Biol. Chem., 259, 1164311646.

38. Markovitz, P.J., Chuang, D.T., 1987. The bifunctional aminoadipic semialdhyde synthase in lysine degradation:Separation of reductase and dehydrogenase domains by limited proteolysis and column chromatography. J. Biol. Chem. 262, 1-6.

39. Miller, L.L., 1962. The role of the liver and the non-hepatic tissues in the regulation of free amino acid levels in the blood. In: Amino Acid Pools:Distribution, Formation, and Function of Free Amino Acids Ed: Holder, J.T., El sevier Publishing Co. NY, 708-721.

40. Millward, D.J., 1989. The nutritional regulation of muscle growth and protein turnover. Aquaculture 79, 1-28.

41. Miron, D., Ben-Yaacov, S., Karchi, H., Galili, G., 1997. In vitro dephosporylation inhibits the activity of soybean lysine-ketoglutarate reductase in a lysine-regulated manner. The Plant J. 12(6), 1453-1458.

42. Muramatsu, K., Takada, R., Uwa, K., 1983. Adaptive responses of liver and kidney lysine-ketoglutarate reductase and lysine oxidation in rats fed graded levels of dietary lysine and casein. Agric. Biol. Chem. 48, 703-711.

43. Noda, C., Ichirara, A., 1978. Purification and properties of L-lysine $\alpha$-ketoglutarate reductase from rat liver mitochondria. Biochim. Biophys. Acta 525, 307-313.

44. Paik, W.K., Pearson, E., Nochumson, S., Kim, S., 1977. Replacement of L-ornithine with L-lysine for urea cycle enzymes. Int. J. Biochem. 197, 13-23.

45. Papes F., Kemper, E.D., Cord-Neto, G., Langone, F., Arruda P., 1999. Lysine degradation through the saccharopine pathway in mammals: involvement of both bifunctional and monofunctional lysine degrading enzymes in mouse. Biochem. J. $344,555-563$.

46. Pegg, A.E., McGill, S., 1979. Decarboxylation of ornithine and lysine in rat tissues. Biochim. Biophys. Acta 568, 416-427.

47. Pink, D., Dixon, W.T., Ball, R.O., 2004. Lysine catabolism in swine: An enzymatic approach. FASEB J. 16:A258.

48. Rodehutscord, M., Mandel, S., Pfeffer, E., 1994. Reduced protein content and use of wheat gluten in diets for rainbow trout: effects on water loading with $\mathrm{N}$ and $\mathrm{P}$.

J. Appl. Ichthyol. 10, 271-273. 
49. Sacksteder, K.A., Biery, B.J., Morrell, J.C., Goodman, B.K., Geisbrecht, B.V., Cox, R.P., Gould, S.J., Geraghty, M.T., 2000. Identification of the $\alpha$-aminoadipic semialdehyde synthase gene, which is defective in familial hyperlysinemia. Am. J. Hum. Gen. 66, 1736-1743.

50. Schimke, R.T., 1962. Differential effects of fasting and non-protein diets on levels of urea cycle enzymes in rat liver. J. Biol. Chem. 237, 1921-1924.

51. Scislowski, P.W.D., Foster, A.R., Fuller, M.F., 1994. Regulation of oxidative degradation of L-lysine in rat liver mitochondria. Biochem. J. 300, 887-891.

52. Shang, Y.C., Tomasso, J., 1990. Aquaculture Economic Analysis: An Introduction. The World Aquaculture Society, Baton Rouge.

53. Shinno, H., Noda, C., Tanaka, K., Ichihara, A., 1980. Induction of L-lysine-2oxoglutarate reductase by glucagon and glucocorticoid in developing and adult rats. Biochim. Biophys. Acta 633, 310-316.

54. Silverstein, J.T., 2004. Using genetic variation to understand control of feed intake in fish. Fish Physiol. Biochem. 27, 173-178.

55. Steidinger, Karen A., 1997. "Pfiesteria piscicida, Other Pfiesteria Species, and Pfiesteria Like Species: A Question of Recognition and Toxicity.” Informational handout prepared July 31, 1997, for the Pocomoke River Fish Health Technical Advisory Committee.

56. Struck, J., Sizer, I.W., 1960. Oxidation of L- $\alpha$-amino acids by chicken liver microsomes. Arch. Bioch. Biophys. 90, 22-30.

57. Tang, G., Zhu, X., Gakiere, B., Levanony, H., Kahana, A., Galili., G., 2002. The bifunctional LKR/SDH locus of plants also encodes a highly active monofunctional lysine-ketoglutarate reductase using a polyadenylation signal located within an intron. Plant. Phys. 130, 147-154.

58. Tesseraud, S. Bihan-Duval, E.L., Peresson, R., Michel, J., Chagneau, A.M., 1997. Response of chick line selected on carcass quality to dietary lysine supply: Live performance and muscle development. Poult. Sci. 78, 80-84.

59. Torres, N., Martinez, L., Aleman, G., Bourges, H. and Tovar, A.R., 1998. Histidase expression is regulated by dietary protein at the pretranslational level in rat liver. $\mathrm{J}$. Nutr. 128, 818-824.

60. Trackman, P.C., Kagan, H.M., 1979. Nonpeptidyl amine inhibitors are substrates of lysyl oxidase. J. Biol. Chem. 254, 7831-7836. 
61. Viola, S., Lahav, E., 1991. Effects of lysine supplementation in practical carp feeds on total protein sparing and reduction in pollution. Isr. J. Aquac.-Bamidgen 43, 112118 .

62. Viola, S., Lahav, E., Angeoni, H., 1992. Reduction of feed protein levels and of nitrogenous $\mathrm{N}$-excretions by lysine supplementation in intensive carp culture. Aquat. Living Resour. 5, 277-285.

63. Walton, M.J., Cowey, C.B. and Adron, J.W., 1984. The effect of dietary lysine levels on growth and metabolism of rainbow trout (Salmo gairdneri). Brit. J. Nutr. 52, 115122.

64. Wang, S., Nesheim, M.C., 1972. Degradation of lysine in chicks. J. Nutr. 102, 384391.

65. Wang, S.H., Crosby, L.O. Nesheim, M.C., 1973. Effect of dietary excesses of lysine and arginine on the degradation of lysine by chicks. J. Nutr. 103, 384-391.

66. Zhu, X., Tang, G., Fabienne, G., Bouchez, D., Galili, G., 2001. A T-DNA insertion knockout of the bifunctional lysine-ketoglutarate reductase/saccharopine dehydrogenase gene elevates lysine levels in Arabidopsis seeds. Plant Phys. 126, 1539-1545.

67. Zhu, X., Tang, G., Galili, G., 2000. Characterization of the two saccharopine dehydrogenase isozymes of lysine catabolism encoded by the single composite AtLKR/SDH locus of Arabidopsis. Plant Phys. 124, 1363-1371. 


\section{Chapter II. Starvation induced alterations in hepatic lysine metabolism in different families of rainbow trout}

\section{Introduction}

Much less is known about lysine oxidation in fish compared to other animals. Lysine catabolism by the lysine $\alpha$-ketoglutarate reductase (LKR) pathway is the presumed major route of lysine degradation in fish, since the LKR pathway is believed to be the predominant pathway for lysine degradation in mammals (Broquist, 1991).

The LKR pathway consists of several enzymatic steps. First, LKR reduces lysine in a NADPH-dependent step to saccharopine. The saccharopine is then oxidized in a NAD+ dependent step to produce $\alpha$-aminoadipate- $\gamma$-semialdehyde and glutamate by saccharopine dehydrogenase (Figure 1). According to cDNA sequence analysis, the LKR and SDH activities are on one bifunctional enzyme in rainbow trout, similar to both plants and mammals (Epelbaum et al., 1997, Papes et al.,1999).

Research on the regulation of LKR activity has mostly been focused in mammals and plants. Papes et al. (1999) reported an increase in LKR mRNA abundance and LKR activity in mice upon injections of lysine. In the same study, starved mice also showed an increase in LKR mRNA and LKR activity relative to fed controls. Interestingly, in plants, phosphorylation-dependent activity has been observed in purified LKR protein from soybeans (Galili et al., 1997). These data support both transcriptional and posttranslational mechanisms for regulating enzyme activity.

In mammals, the activity of many amino acid degrading enzymes increases as protein intake increases (Harper, 1965), which is similar in fish (Kim et al., 1992). Interestingly, Walton (1984) reported no significant increase in hepatic LKR activity for 
rainbow trout fed increasing levels of dietary lysine, although LKR activity tended to increase with increasing dietary lysine. These data contradict what has been reported for rats and chickens (Chu et al., 1976, Wang et al., 1973).

Further knowledge of lysine degradation may have significant value in the future to the aquaculture industry. Understanding the basic mechanisms of lysine degradation and specifically LKR activity may enable the development of genetic tools to manipulate lysine degradation. This study investigates the regulation of LKR activity and lysine oxidation in rainbow trout. The effects of fasting on hepatic LKR activity, mRNA levels and lysine oxidation are examined. Moreover, since genetically improved strains have a great potential to influence fish production, these studies were performed in 4 genetic lines of RBT selected for feed efficiency to determine if there were relationships between lysine metabolism and fish performance. 


\section{Materials and Methods}

\section{$\underline{\text { Reagents and Chemicals }}$}

Commercial fish feed was purchased from Ziegler Brothers, Inc. (Gardners, PA). Triton X-100, L-lysine monohydrochloride and 2-mercaptoethanol were purchased from Fisher Scientific (Fair Lawn, New Jersey). $\left[\mathrm{U}-{ }^{14} \mathrm{C}\right] \mathrm{L}-\mathrm{lysine}$ was from American Radiolabel Chemicals Inc. (St. Louis, MO). Biosafe-II scintillation fluid was from Research Products Inc. (Mount Prospect, IL). SYBR Green was obtained from Molecular Probes (Eugene, Oregon). IQ Supermix and flourescein was from Biorad (Hercules, CA). Random primers, RQ1 RNase free DNase and M-MLV Reverse Transcriptase were from Promega Corp. (Madison, WI). Trizol, 125:24:1 phenol acid, chloroform, isoamyl alcohol and 25:24:1 phenol, chloroform, isoamyl alcohol were from Ambion (Austin, TX). Gene specific primers were synthesized by Invitrogen (Carlsbad, CA). All other reagents were from Sigma-Aldrich (St. Louis, MO).

\section{$\underline{\text { Fish }}$}

Two strains of rainbow trout, Oncorhynchus mykiss, were used. Strain A originated from the alpine lakes in Washington State. Strain B was developed from a cross between a Puget Sound Steelhead and a Canadian Kamloops strain. Through selective breeding, the National Center for Cool and Cold Water Aquaculture (NCCCWA) generated 11 fullsib families total, 5 families from strain A and 6 from Strain B. In a preliminary study, a high and low feed efficiency family was identified within both strains for a total of 4 families (Table 1). The efficiency classifications were based on a 5 week feeding trial using 5 individually housed fish from each family. The fish weighed approximately 2-4 
$\mathrm{g}$ and grew to approximately $10 \mathrm{~g}$ during the preliminary study. The other family members remained in a group tank until the start of the primary study.

Within each of the 4 families, fish were randomly selected from the group tank until 8 fish of similar weight were obtained. The approximate weight of the fish was $70 \mathrm{~g}$. All 32 fish were randomly distributed into individual tanks. A closed recirculating system using a biofilter replaced $15 \%$ of the water daily. The dissolved oxygen content was near saturation. Water temperature ranged from $14.3-14.8{ }^{\circ} \mathrm{C}$ and a twelve hour light cycle was used.

\section{Experimental Design}

The study began on 12 August 2003 . Fish were fed $2 \%$ of their body weight for a 2 week acclimation period. All fish were fed a commercial diet (Table 2). Two fish did not start eating and were not replaced. However, their data are excluded from the statistical analysis. After the acclimation period, all fish continued to be fed $2 \%$ of their body weight per day for the next 3 weeks. At the end of 3 weeks, 4 fish from each family were randomly selected to be starved for 2 weeks. At the end of the starvation period, all 32 fish were harvested. The fed fish received their final meal 24 hours prior to harvest. Body and liver weight were recorded for each fish. The upper lobe of liver was snap frozen in liquid nitrogen and the remaining liver placed in ice cold $\mathrm{H}$ buffer ( $5 \mathrm{mM}$ Hepes, 5 mM 2-mercaptoethanol, 1 mM EGTA, 220 mM Mannitol, 70 mM Sucrose, $0.05 \%(\mathrm{w} / \mathrm{v})$ bovine serum albumin, $\mathrm{pH}=7.4)$. The livers in $\mathrm{H}$ buffer were transported on ice from Leetown, WV to Morgantown, WV. Snap frozen tissue was kept at $-80^{\circ} \mathrm{C}$ 
until RNA was extracted. The LKR activity and lysine oxidation assays were performed the day the fish were harvested.

\section{$\underline{\text { Lysine Oxidation Assay }}$}

In vitro hepatic lysine oxidation was assessed by measuring the recovery of ${ }^{14} \mathrm{CO}_{2}$ from $\left[\mathrm{U}-{ }^{14} \mathrm{C}\right] \mathrm{L}-$ lysine in a procedure described by Blemings et al. (1998). Using the polytron, each liver was homogenized in enough $\mathrm{H}$ Buffer to make a 25\% (w/v) homogenate. Incubations were started when homogenate $(1 \mathrm{ml})$ was added to a $25 \mathrm{ml}$ Erlenmeyer flask containing the following reagents(final concentrations): $10 \mathrm{mM} \mathrm{L}$ lysine- $\mathrm{HCl}, 10 \mathrm{mM}$ HEPES, $3 \mathrm{mM} \mathrm{MgCl} 2,0.2 \mathrm{mM}$ EDTA, $182 \mathrm{mM}$ mannitol and 61

$\mathrm{mM}$ sucrose. The specific activity of $\left[\mathrm{U}_{-}{ }^{14} \mathrm{C}\right] \mathrm{L}-\mathrm{lysine}$ was $4.2 \mathrm{~Bq} / \mathrm{nmol}$. Reactions were incubated for 30 minutes, while shaking $(100$ oscillations $/ \mathrm{min})$ in a water bath $\left(25-27^{\circ} \mathrm{C}\right)$. Carbon dioxide was trapped in an Eppendorf tube containing $0.5 \mathrm{ml}$ of base trap solution (ethanolamine and methylcellosolve, 1:2). To terminate the reactions, $0.5 \mathrm{ml}$ of $35 \%$ perchloric acid was injected through serum caps covering the flasks. To ensure maximal recovery of ${ }^{14} \mathrm{CO}_{2}$, flasks remained in the water bath with continuous shaking for an additional 180 minutes. Eppendorf tubes were removed, placed in $17 \mathrm{ml}$ of Biosafe-II scintillation fluid and vortexed. Radioactivity was determined in a Beckman LS 6500 (Beckman Coulter Inc, Somerset, NJ) liquid scintillation counter. The average of duplicate measures for each liver was used to determine total in-vitro hepatic lysine oxidation. 


\section{$\underline{\text { Lysine } \alpha \text {-Ketoglutarate Reductase Assay }}$}

LKR activity was measured spectrophotometrically as lysine-dependent NADPH oxidation; this procedure was first described by Hutzler and Dancis (1968), performed on fish liver by Walton et al. (1984) and later modified in rat by Blemings et al. (1994). The change in absorbance is converted to activity using the Lambert-Beer Law (Eq.1). Using the polytron, each liver was homogenized in enough $\mathrm{H}$ Buffer to make a $25 \%$ (w/v) homogenate. Enzyme activity was assayed when $25 \mu 1$ of homogenate was added to a cuvette containing $825 \mu$ of $127.5 \mathrm{mM}$ HEPES, $114.75 \mathrm{mM}$ mannitol, $38.25 \mathrm{mM}$ sucrose, $4.25 \mathrm{mM}$ 2-mercaptoethanol, $0.0425 \%$ (w/v) bovine serum albumin, $0.21 \mathrm{mM}$ NADPH, $12.75 \mathrm{mM} \alpha$-ketoglutarate and $0.29 \%$ triton-X 100 (final concentrations). 100 $\mu \mathrm{l}$ of 400-M L-lysine or water was then added to bring the final volume to $1 \mathrm{ml}$. The cuvette top was sealed with parafilm and gently inverted three times. The final concentration of lysine was $40 \mathrm{mM}$. The reported Michaelis-Menton Constant $\left(\mathrm{K}_{\mathrm{m}}\right)$ of trout LKR is $7.3 \mathrm{mM}$ for lysine and $0.5 \mathrm{mM}$ for $\alpha$-ketoglutarate (Walton et al., 1984). Each assay consisted of 2 cuvettes with lysine and 2 cuvettes with water. Each liver homogenate was assayed in duplicate. The assay is linear for 3 minutes.

\section{$\underline{\text { Real time PCR }}$}

Primers were designed to rainbow trout LKR based on rainbow trout sequence provided by the NCCCWA. Acidic Ribosomal Protein $\mathrm{P}_{\mathrm{o}}(\mathrm{ARP})$ was used for the housekeeping gene. ARP primers were previously used in another salmonid (Pierce et al., 2004). The PCR products for LKR and ARP were 113 and 112 base pairs, respectively. PCR products were sequenced and primers confirmed to be specific. 
PCR efficiencies for LKR and ARP were determined by using serial dilutions of cDNA spanning 3 orders of magnitude (Table 3 ). Critical threshold $\left(C_{t}\right)$ values were determined from the amplification plots for LKR (Fig. 2a) and for ARP (Fig. 2b). Critical threshold is the PCR cycle where the fluorescence significantly increases from the baseline value established during the first 10 cycles. Melt curve analysis showed a single product for both LKR (Fig. 3a) and ARP (Fig. 3b) with no "primer dimers" even at low cDNA concentrations. The $\mathrm{C}_{t}$ values of the dilution series were plotted against the log amount of template cDNA in a PCR reaction for LKR (Fig. 4a) and ARP (Fig. 4b). The amount of cDNA was estimated from the amount of total RNA $(2 \mu \mathrm{g})$ used in a reverse transciptase reaction, followed 7 serial dilutions of cDNA. PCR efficiency was determined from the slope of the regression line by the equation $E=10^{(-1 / \text { slope })}$. A slope of -3.322 represents a $100 \%$ efficient PCR reaction because there are 3.32 cycles between 10 fold $(1 \log )$ changes in amplicon copies. Hence, substitution of -3.322 into $\mathrm{E}=10^{(-1 / \text { slope })}$ yields an efficiency of 2 or in other words the template doubles after each cycle during exponential amplification. ARP efficiency is $1.84 \pm 0.02$ and LKR efficiency is $1.95 \pm 0.02$. Intra-assay and inter-assay coefficient of variation is $23 \%$ and $18 \%$ for transformed $\mathrm{C}_{\mathrm{t}}$ values.

Approximately $200 \mathrm{mg}$ of frozen liver from each fish was used to isolate total RNA. RNA was extracted using TRIZOL (Ambion Inc., Austin, TX) followed by two washes with a 125:24:1 mixture of acid phenol, chloroform and isoamyl alcohol (Ambion, Inc., Austin, TX) and two washes with a 25: 24:1 mixture of phenol, chloroform and isoamyl alcohol (Ambion, Inc., Austin, TX). For determination of $\mathrm{C}_{\mathrm{t}}$ values, 8 livers, one from each treatment within each family, were processed and assayed together at one time. 
RNA quality was assessed using $\mathrm{OD}_{260} / \mathrm{OD}_{280} \mathrm{~nm}$ absorption ratio and a denaturing gel containing 2.2 M formaldehyde. Ten $\mu 1$ from each RNA sample was pooled to create a pooled reference sample. This pool was used with each reverse transcription reaction and real time PCR to serve as a correction factor for inter-assay variation due to differences in reverse transcription efficiencies. For each liver sample and the pool, $2 \mu \mathrm{g}$ of total RNA was DNase treated with 2 units of RQ1 RNase-Free DNase (Promega Corp., Madison, WI) and reverse transcribed using $1 \mu \mathrm{g}$ random primers (Promega Corp., Madison,WI) and 200 units of M-MLV reverse transcriptase (Promega Corp., Madison, WI). The cDNA was diluted to the middle of the regression curve from which PCR efficiencies were determined.

Each cDNA sample was analyzed in separate reaction tubes for LKR and ARP in

triplicate PCR reactions $\left(30 \mathrm{~s} 95^{\circ} \mathrm{C} \rightarrow 30 \mathrm{~s} 57^{\circ} \mathrm{C} \rightarrow 30 \mathrm{~s} 72^{\circ} \mathrm{C}\right.$ for 40 cycles) on the same 96-well plate. The pooled cDNA was included on the plate in the same manner. A total of 4 plates was needed for all 32 livers. Real time PCR reactions contained $12.5 \mu 1$ of BioRad IQ Supermix, $0.5 \mu$ forward LKR primer $(50 \mu \mathrm{M})$ or ARP primer $(25 \mu \mathrm{M})$, $0.5 \mu 1$ reverse LKR primer $(50 \mu \mathrm{M})$ or ARP primer $(25 \mu \mathrm{M}), 0.25 \mu 1$ fluorescein $(1 \mu \mathrm{M})$, $2.5 \mu 1$ SYBR Green (diluted: 1x10,000), $6.75 \mu 1$ DEPC treated water and $2 \mu 1$ of cDNA. Data were analyzed using an "efficiency corrected relative expression" method (Pfaffl, M., 2001, Equation 2).

\section{$\underline{\text { Statistics }}$}

Statistical significance was assessed using analysis of variance with PC-SAS General Linear Models. The effects of strain, family within strain and starvation were tested, as 
well as, the interaction between strain and starvation and starvation within strain by family. A 3 factor randomized design was used. In the event of a significant $F(p<0.05)$, Fisher's LSD was used for means comparison. Correlation was tested using Pearson's correlation coefficients. The housekeeping gene ARP was assessed for significant difference due to starvation using $\mathrm{X}^{2}$ analysis. $\mathrm{O}$ 


\section{Results}

Feed conversion ratios (FCR) for the preliminary study and the primary study are shown in Table 5. For the primary study, only the high efficiency family selected from strain B remained more efficient than the low efficiency family $(\mathrm{p}<0.06)$. Both low efficiency families had lower (improved) FCRs in the primary study compared to the preliminary study. However, there was a significant effect of family within strain for weight gain (Fig. 5). For strain A, the average weight gain of fed fish for the high and low feed efficiency families was $72.6 \pm 5.1$ and $41.5 \pm 2.0 \mathrm{~g}$, respectively (Fig. 5). For strain $\mathrm{B}$, the average weight gain of fed fish for the high and low feed efficiency families was $78.8 \pm 6.4$ and $70.5 \pm 1.0$ g, respectively (Fig. 5). The 2 week starvation period significantly decreased weight gain and there is a significant interaction between strain and starvation for weight gain (Fig. 5).

Starved fish have a significantly smaller relative liver size (RLS) (Fig. 6). The mean RLS for starved fish was $0.80 \pm 0.08 \%$ compared to $1.85 \pm 0.09 \%$ for fed fish. On average, strain A has a larger RLS that strain B $(\mathrm{p}<0.01)$ (Table 6). Moreover, the RLS of families within strain are significantly different (Fig. 6). For strain A, the RLS for the high and low efficiency families are $1.13+0.18 \%$ and $1.71+0.42 \%$. For strain B, the RLS for the high and low efficiency families are $1.25+0.2 \%$ and $1.04+0.12 \%$.

No significant differences were detected for in-vitro hepatic lysine oxidation between fed and starved fish (Fig. 7). Starved fish tended to oxidize more lysine than fed fish on a per gram tissue basis. The mean lysine oxidation for fed and starved fish was $1165 \pm 454$ and $2217 \pm 420 \mathrm{pmol}$ lysine oxidized / min* gram liver (Table 6). However, when these data are expressed relative to total liver weight, hepatic lysine oxidation for fed fish 
surpasses starved fish at $2935 \pm 659$ compared to $1499 \pm 610 \mathrm{pmol}$ lysine oxidized $/ \mathrm{min}$, respectively (Table 6).

LKR activity for starved and fed fish was not significantly different when expressed per gram of liver (Fig. 9). The mean LKR activity for fed and fasted fish was $104 \pm 33$ and $150 \pm 31 \mathrm{nmol}$ lysine degraded/min*gm liver, respectively (Table 6). These same data scaled to total liver wet weight indicate that LKR activity is significantly less in the fasted fish (Fig. 10). Total hepatic LKR activity for fed fish is $272 \pm 58$ compared to $103+53 \mathrm{nmol}$ lysine degraded/min for fasted fish (Table 6). Neither strain, nor family had any significant effect on lysine oxidation or LKR activity. No interactions were detected.

Across both strains, fish not fed for 2 wks had significantly less LKR mRNA compared to fed fish $(\mathrm{p}<0.01)$. LKR mRNA abundance was not significantly different for high and low feed efficiency families within a strain. However, strain B pooled across both feeding levels had significantly more message than Strain A $(p<0.05)$. LKR mRNA abundance was not correlated to LKR activity or lysine oxidation but was positively correlated to weight gain $(\mathrm{p}<0.01)$. 


\section{Discussion}

Among salmonid fish, growth efficiency can greatly vary (Carter et al., 1993, McCarthy et al., 1993). The genetic variance measured by the amount of heterozygosity and allelic diversity is very high among rainbow trout (Silverstein et al., 2004); the more genetic variance in a population the greater the potential for selective improvement. As expected, genotype influences growth efficiency in fish, therefore, selecting more efficient strains can offer great economic benefits (Gjedrem, 2000). However, strain development for more efficient RBT has been slow due to the difficulty associated with measuring feed intake in fish.

Identifying metabolic mechanisms that may be responsible for phenotypic variation is important for strain development. Studies of physiological and genetic variables may help to elucidate how complex traits, like feed efficiency, are regulated (Silverstein, 2002). In the current study, effects of selecting families with divergent feed efficiencies were seen. For the low efficiency families the FCR changed as the fish aged. For both strains, the low efficiency families improved their FCR with age, while high efficiency families changed very little (Table 5). Although the low efficiency family for strain A had a better FCR for the primary study than the high efficiency family, fish from the high efficiency family gained significantly more weight than the strain A low efficiency family.

Genotype may influence lysine metabolism. Lysine oxidation and LKR activity (per gram of liver) was not significantly different between the strains. However, the strains had significantly different amounts of LKR mRNA. Pooled across both feed levels, strain B had 55\% more LKR mRNA than strain A $(\mathrm{p}<0.01)$. 
Similar to other food withdrawal studies (Kim et al.1992, Foster et al. 1991), the starved fish here had smaller RLS ( $<0.001)$. Most livers from the starved fish weighed less than one gram. This size reduction usually reflects a decrease in cell size rather than cell number (Foster et al., 1991). However, size differences influence the interpretation of the LKR activity and lysine oxidation data. LKR activity expressed per gram of liver is on average $50 \%$ higher in starved fish relative to fed fish. However, the same data scaled to total liver wet weight shows greater than 2-fold increase in the activity of fed fish relative to starved fish. Findings of this nature have been reported in fasting studies for other amino acid catabolizing enzymes. Kim et al. (1992) found that there was no significant difference in glutamate dehydrogenase activity between 12-day fasted RBT fingerlings and fingerlings fed commercial diet when the data was scaled to body weight. However, a 2-fold increase in activity was observed for fasted fingerlings when enzyme activity was scaled to either gram of liver or protein, respectively. Data expressed relative to total liver or body weight may not be the best estimate of LKR activity in fasting studies. RLS for fed fish were at the least twice as large as fasted fish. Moreover, total hepatic LKR activity is positively correlated to RLS ( $<<0.01$ ), thus these estimates are a function of size and may not provide an accurate estimate of the cellular changes occurring.

LKR is a mitochondrial enzyme in rat (Blemings et al., 1998) and has been suggested as such for rainbow trout (Walton, 1984). Interestingly, the LKR activity for both the fed and starved fish is approximately 1000 -fold greater than the oxidation data, consistent with a mitochondrial location for LKR in rainbow trout liver. Blemings et al. (1998) found that lysine oxidation in mitochondria is transport limited in rat liver thus in 
trout liver total lysine oxidation may have been transport limited, as well. Moreover, using a subcellular targeting peptide prediction program (Emanuelsson et al., 2000), a mitochondrial targeting peptide was identified in the first 150 amino acids of rainbow trout LKR sequence.

The activity of many amino acid catabolizing enzymes changes in response to nutrient intake. Starvation and high protein diets will generally increase the activity of amino acid degrading enzymes, whereas low-protein or protein-free diets will result in a decrease in activity (Harper, 1965). A 12-day fast of RBT fingerlings caused a significant increase in alanine aminotransferase, histidase and glutamate dehydrogenase, however, only histidase activity increased in fingerlings fed a high protein $(50 \% \mathrm{CP})$ diet (Kim et al., 1992). Interestingly, amino acid degrading enzymes respond differently to the presence or absence of their respective amino acid substrate. For example, rats fed a lysine free diet had a significantly reduced hepatic LKR activity compared to rats fed a protein-free or complete amino acid diet; whereas, there were no significant differences in theronine dehydratase activity among rats fed a threonine-free diet, protein free diet or complete amino acid diet (Chu et al., 1975).

LKR activity is perhaps modulated differently from other amino acid-degrading enzymes. For example, histidase mRNA, in-vitro activity and protein levels have been found to increase in rats fed increasing amounts of protein in their diet, however, increasing the amount of histidine alone resulted in no increases (Torres et al., 1998). Contrary to histidase, LKR activity and LKR mRNA increase in mice receiving lysine injections or diets containing excess lysine (Papes et al., 1999). Moreover, Papes et al. (1999) observed an 80\% increase in LKR mRNA and 52\% increase in LKR activity in 
mice starved for 1 or 2 days relative to fed mice. The concomitant increase in LKR activity and LKR mRNA suggests enzyme activity is transcriptionally regulated. Here, we report a $68 \%$ decrease in LKR mRNA for fasted fish and a 50\% increase in activity relative to fed fish. Although these results seem paradoxical several explanations are possible.

First, the amount of mRNA does not necessarily relate to the amount of active LKR protein. The amount of LKR protein could have remained constant while a posttranslational modification may have increased its activity. Phosphorylation-dependent activity of LKR has been reported in soybean (Miron et al., 1997). Moreover, amino acid analysis of RBT, mouse and human LKR revealed potential threonine and serine phosphorylation sites at the LKR and SDH domains, respectfully. Since antibodies for rainbow trout LKR are unavailable, it is not possible to quantify protein levels at this time. However, in mice fed increasing amounts of casein (a milk protein), Keiss et al. (2004) reported a 2 -fold increase in LKR activity accompanied by an increase a $10 \%$ increase in LKR mRNA abundance and 20\% increase in LKR protein abundance.

Second, during times of starvation, protein degradation would elevate blood lysine concentration increasing liver lysine concentration and therefore increasing flux thru the LKR pathway. The $\mathrm{K}_{\mathrm{m}}$ for rainbow trout LKR is estimated to be $7.3 \mathrm{mM}$ (Walton et al., 1984). This is well above the estimated lysine concentration in the blood of mammals at $200 \mu \mathrm{M}$ and $4 \mathrm{mM}$ in liver mitochondria (Blemings et al., 1998). Therefore, LKR activity is probably substrate limited in rainbow trout. Increasing LKR mRNA may not be necessary to increase the rate at which lysine is degraded since under in vivo conditions, substrate (lysine) concentration is well below the $\mathrm{K}_{\mathrm{m}}$. 
Third, the differences between these data and the results of Papes et al. (1999) may be a function of the relative state of starvation. The mice were starved for 1 or 2 days in contrast to a 2 week starvation period for the fish in this study. Certainly, homeothermic mice and poikilothermic fish are metabolically different. A RBT can withstand several weeks of starvation whereas a mouse could not. The cellular response time to an environmental stress, such as starvation, may be different for fish compared to mammals. Fish enter into a period of hypometabolism when food is limited. Foster et al. (1991) reported an overall decrease in hepatocyte $\mathrm{CO}_{2}$ production in perch starved for 7 weeks. The regulation of this metabolic flux between between periods of hypometabolism and hypermetabolism may be exceptionally adapted for animals who survive long periods of limited food intake.

Since carnivorous fish use protein for their primary energy source, amino acid oxidation may be less tightly regulated than in mammals where amino acids are primarily used for protein synthesis (Kim et al., 1992). The response of metabolic pathways to stressors, such as fasting, may help to discern how amino acid oxidation is regulated. Moreover, by examining the regulation of lysine degradation among different breeds or strains, we are more likely to identify the genetic differences which may be exploited to increase efficiency of lysine use for protein synthesis. In the future, decreasing the rate of lysine degradation would not only benefit the farmers by reducing feed costs but would benefit the environment by reducing nutrient losses to the ecosystem. In future studies, increasing the number of experimental units may be necessary to see significant differences in genetic lines of rainbow trout. Moreover, evaluating LKR activity, mRNA 
and protein throughout the starvation period may help to elucidate the roles nutrients and genetics may have in regulating the lysine oxidation in rainbow trout. 


\section{Table 1. Strains and families}

\begin{tabular}{|c|c|c|}
\hline Strain & $\begin{array}{c}\text { High Efficiency } \\
\text { Family }\end{array}$ & $\begin{array}{c}\text { Low Efficiency } \\
\text { Family }\end{array}$ \\
\hline $\begin{array}{c}\text { A } \\
\text { (alpine lakes origin) }\end{array}$ & A84 & A103 \\
\hline $\begin{array}{c}\text { B } \\
\text { (Puget Sound Steelhead X } \\
\text { Canadian Kamloops) }\end{array}$ & B56 \\
\hline
\end{tabular}


Table 2. Composition of Feed

\begin{tabular}{|l|l|}
\hline Zeigler Gold Floating: 3.0MM (1/8) & \% in Feed \\
\hline Crude Protein & 42 \\
\hline Crude Fat & 16 \\
\hline Crude Fiber & 4.0 \\
\hline Digestable Energy & $3870 \mathrm{Kcal} / \mathrm{Kg}$ \\
\hline Metabolizable Energy & $3540 \mathrm{Kcal} / \mathrm{Kg}$ \\
\hline
\end{tabular}


Table 3. Primer Sequences and PCR Efficiencies

\begin{tabular}{|c|c|c|c|c|}
\hline \multicolumn{3}{|r|}{ Sequence $5^{\prime} \rightarrow 3^{\prime}$} & Length & Eff. \\
\hline LKR & $\begin{array}{l}\text { F primer } \\
\text { R Primer }\end{array}$ & $\begin{array}{l}\text { GCG AGT GCT ACT ACT GGG TTC } \\
\text { CCT CTG CCT GGG TCA ACA AC }\end{array}$ & $\begin{array}{l}113 \\
b p\end{array}$ & 1.95 \\
\hline ARP & $\begin{array}{l}\text { F Primer } \\
\text { R Primer }\end{array}$ & $\begin{array}{l}\text { GAA AAT CAT CCA CTT GCT GGA TG } \\
\text { CTT CCC ACG CAA GGA CAG A }\end{array}$ & $\begin{array}{l}112 \\
b p\end{array}$ & 1.84 \\
\hline
\end{tabular}


Table 4. Inter and Intra-Assay Variation

INTER ASSAY

INTRA ASSAY

\begin{tabular}{|c|c|c|c|c|c|c|}
\hline & Mean Ct & SEM & \%CV & Mean Ct & SEM & \%CV \\
\hline LKR & 30.7 & 0.08 & $\mathbf{1 8}$ & 30.7 & 0.2 & $\mathbf{2 2 . 7}$ \\
\hline ARP & 25.7 & 0.03 & $\mathbf{7 . 3}$ & 25.6 & 0.1 & $\mathbf{1 5 . 2}$ \\
\hline
\end{tabular}

For determination of variation, $2 \mu \mathrm{g}$ of total RNA was reverse transcribed. The cDNA was then diluted 5-fold and used as template for real time PCR ( $\mathrm{n}=3$ PCR reactions for each). 
Table 5. Feed Conversion Ratios (FCRs)

\begin{tabular}{|lcc|}
\hline Efficiency & $\begin{array}{c}\text { FCR } \\
\text { Preliminary } \\
\text { Study }\end{array}$ & $\begin{array}{c}\text { FCR } \\
\text { Primary } \\
\text { Study }\end{array}$ \\
\hline Strain A & & \\
& & \\
Low & $0.98 \pm 0.08^{*}$ & $0.71 \pm 0.03$ \\
High & $0.81 \pm 0.04$ & $0.79 \pm 0.18$ \\
Strain B & & \\
Low & & \\
High & $1.13 \pm 0.14^{* *}$ & $0.89 \pm 0.04^{*}$ \\
& $0.75 \pm 0.15$ & $0.78 \pm 0.02$ \\
\hline
\end{tabular}

FCRs were calculated as feed consumed per weight gained for 5 weeks. The preliminary FCRs were calculated from fish weighing approximated $2 \mathrm{~g}$ and growing to approximately $10 \mathrm{~g}$. Each FCR represents the mean of 5 individually housed fish. The primary FCRs were calculated over the course of this study from the fish that received food for the entire 5 week period. Each FCR represents the average of 4 individually housed fish for Strain B and 3 individually house fish for strain A. Within each column: $* p<0.10 * * p<0.05$ applies to comparisons made within a strain for each study. 
Table 6. Data Summary

\begin{tabular}{|c|c|c|c|c|c|c|c|}
\hline & \multirow[b]{2}{*}{$\mathrm{N}$} & \multirow{2}{*}{$\begin{array}{c}\mathbf{B W} \\
\mathrm{g}\end{array}$} & \multirow{2}{*}{$\begin{array}{c}\text { RLS } \\
\%\end{array}$} & \multicolumn{2}{|c|}{ Lysine Oxd. } & \multicolumn{2}{|c|}{ LKR Activity } \\
\hline & & & & g liver & per liver & $\mathrm{g}$ liver & per liver \\
\hline Fed & 14 & $65.8 \pm 3$ & $1.85 \pm .09$ & $1165 \pm 454$ & $2935 \pm 659$ & $104 \pm 34$ & $272 \pm 58$ \\
\hline Fasted & 16 & $22.2 \pm 3$ & $0.80 \pm .08$ & $2217 \pm 420$ & $1499 \pm 610$ & $150 \pm 31$ & $103 \pm 54$ \\
\hline A & 14 & $40.7 \pm 3$ & $1.51 \pm .09$ & $1530+454$ & $1779 \pm 659$ & $125+33$ & $210+58$ \\
\hline B & 16 & $47.5 \pm 3$ & $1.15 \pm .08$ & $1852+420$ & $2655 \pm 610$ & $129 \pm 31$ & $166 \pm 54$ \\
\hline
\end{tabular}

Variables: N (\# of individual fish), BW( weight gained), RLS(relative liver size, liver weight g/ total body weight g), Lysine Oxd. (lysine oxidation, expressed as either pmoles of lysine degraded per minute per gram of liver or pmoles of lysine degraded per minute), LKR activity (expressed as either nmoles of lysine degraded per minute per gram of liver or nmoles of lysine degraded per minute). Each value is the mean + SEM. 


\section{Equation 1. Determination of LKR activity}

$\Delta$ Absorbance $=\varepsilon * \mathbf{b} * \Delta$ concentration (disappearance of NADPH)

Rearrange and Substitute:

$\Delta$ concentration $($ moles $/ \min * \mathbf{L})=\Delta$ Absorbance $/ \varepsilon * \mathbf{b}$

$\Delta$ Aborbance $=(+$ lysine $) \mathrm{nm}-(-1 \mathrm{ysine}) \mathrm{nm}$

$\varepsilon=6222 \mathrm{~L} / \mathrm{cm}^{*} \mathrm{~mol}$

$\mathrm{b}=1 \mathrm{~cm}$

Multiply:

$\Delta$ concentration $(\operatorname{moles} / \mathrm{min} * \mathbf{L}) *$ total volume of cuvette $(\mathrm{L})=\Delta \mathrm{moles} / \mathrm{min}$

Determine amount of liver in cuvette:

A $25 \%(w / v)$ homogenate was used:

$0.25 \mathrm{gm}$ liver $/ \mathrm{ml} * \mathbf{0 . 0 2 5} \mathrm{ml}$ homogenate/cuvette $=\mathbf{0 . 0 0 6 2 5} \mathrm{gm}$ liver/ cuvette

Multiply:

$\Delta$ Moles $/ \mathrm{min} * 1 /$ gram liver in cuvette $=\Delta$ moles of $\mathrm{NADPH} / \mathrm{min} * \mathrm{gm}$ liver Activity $=\Delta$ moles of NADPH $/$ min* gm liver 


\section{Equation 2. Efficiency Corrected Relative Expression Equation}

Ratio $=\frac{\mathrm{E}_{(\mathrm{LKR})}}{\mathrm{E}_{(\mathrm{ARP})}} \frac{\Delta \mathrm{Ct} \mathrm{LKR} \text { (control-treatment) }}{\Delta \mathrm{Ct} \text { ARP (control-treatment) }}$

Where

$\mathrm{E}=$ PCR efficiency

$\mathrm{C}_{\mathrm{t}}=$ Critical threshold

(Pfaffl, M.W., 2001).

For this experiment, control $\mathrm{C}_{\mathrm{t}}$ is the value from the pooled sample on each plate. This corrects for inter-assay variation as a result of RT efficiency and plate variation. 
Figure 1. Initial Enzymatic Reactions in LKR pathway

\section{Lysine}
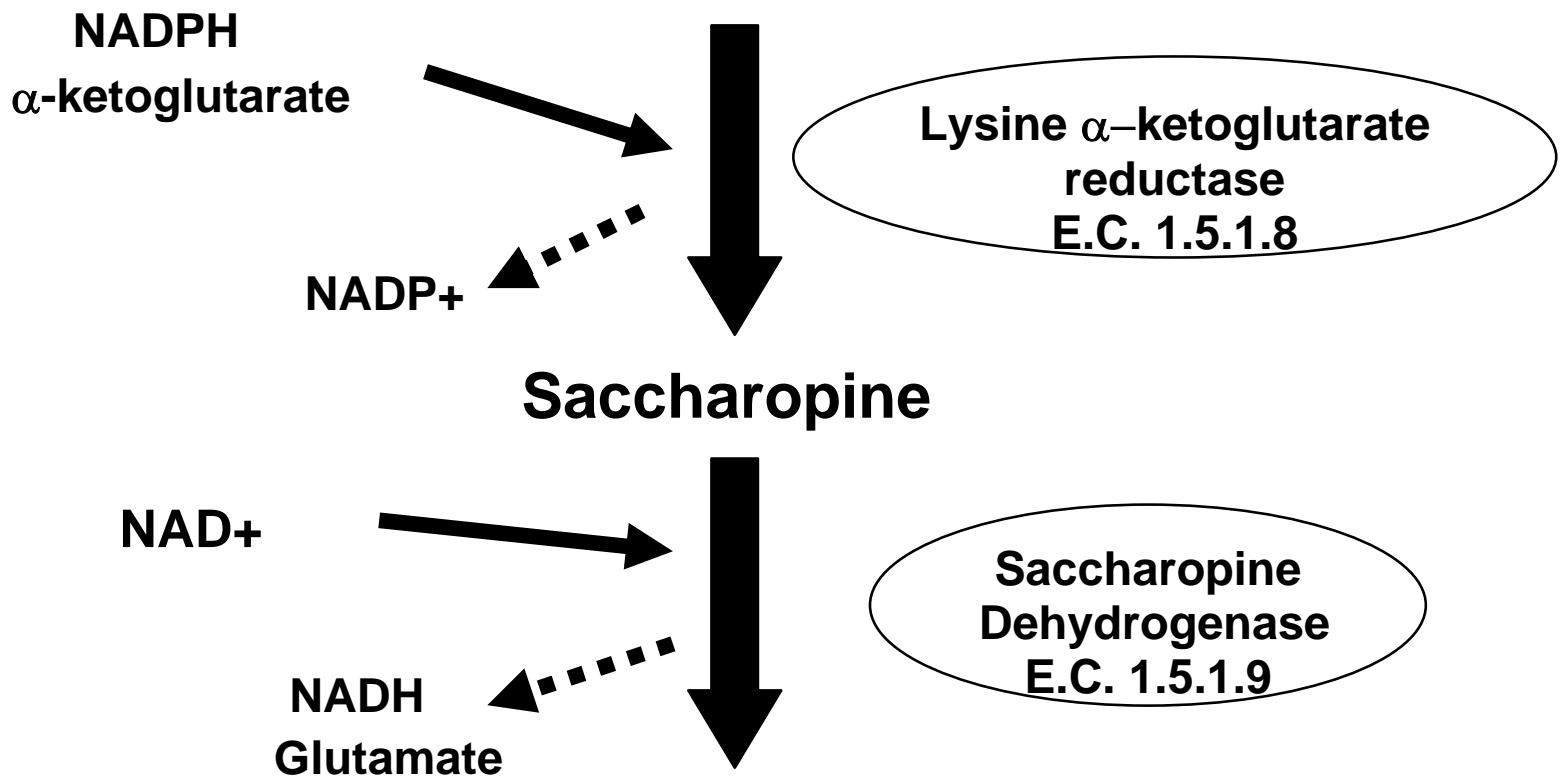

$\alpha$-Aminoadipate- $\gamma$-semidaldehyde 
Figure 2a. LKR amplification plot of serially diluted cDNA

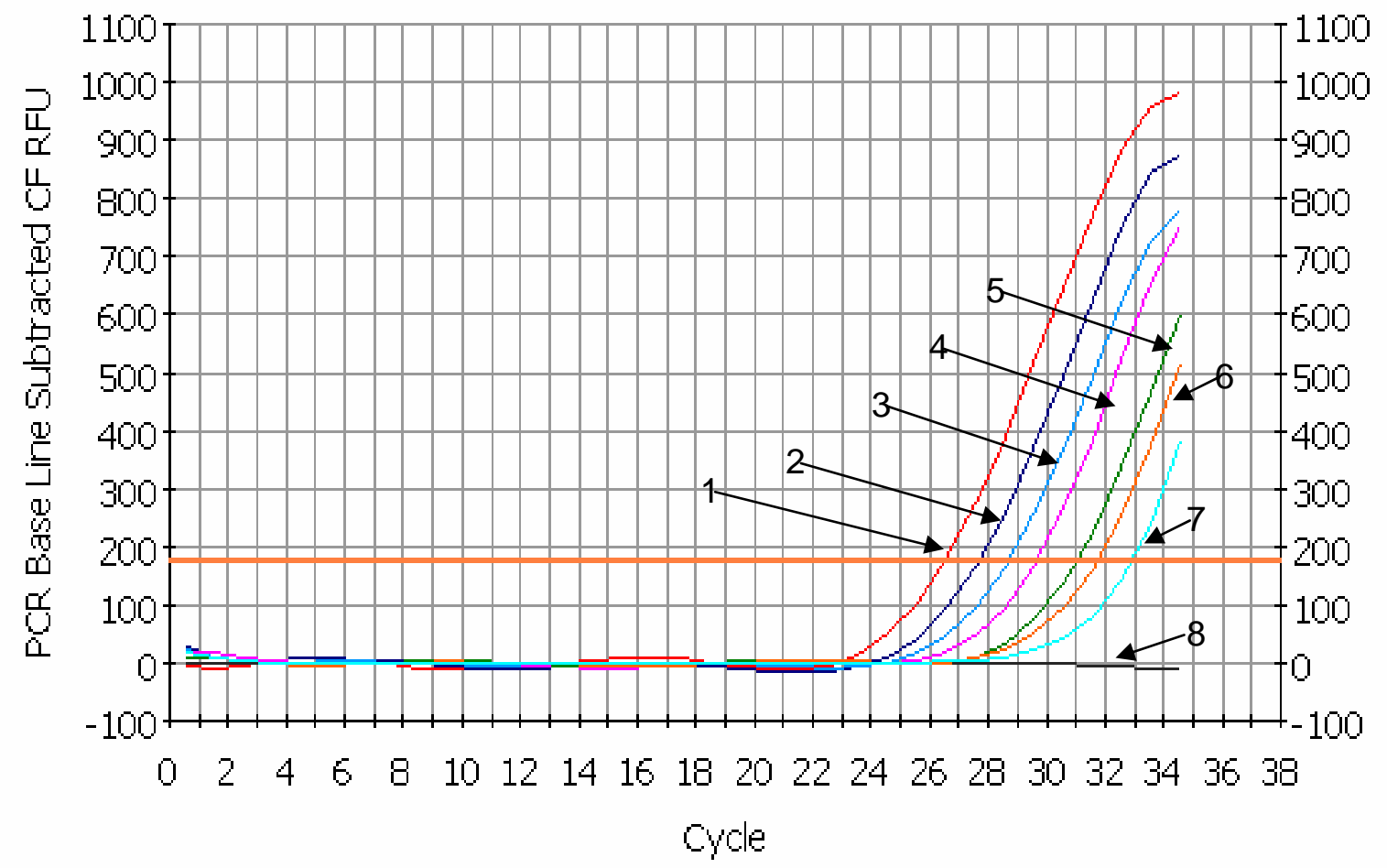

PCR Amplification ws Cycle: Data 22-Sep-03 0946 CV1.opd

Each line represents one PCR reaction. Lines 1-7 are derived from reactions containing 2 $\mu 1$ of template from a serial dilution starting with cDNA made with $2 \mu \mathrm{g}$ of total RNA and diluted 2 -fold for each line. Line 8 represents no template. 


\section{Figure 2b. ARP Amplification Plot of serially diluted cDNA}

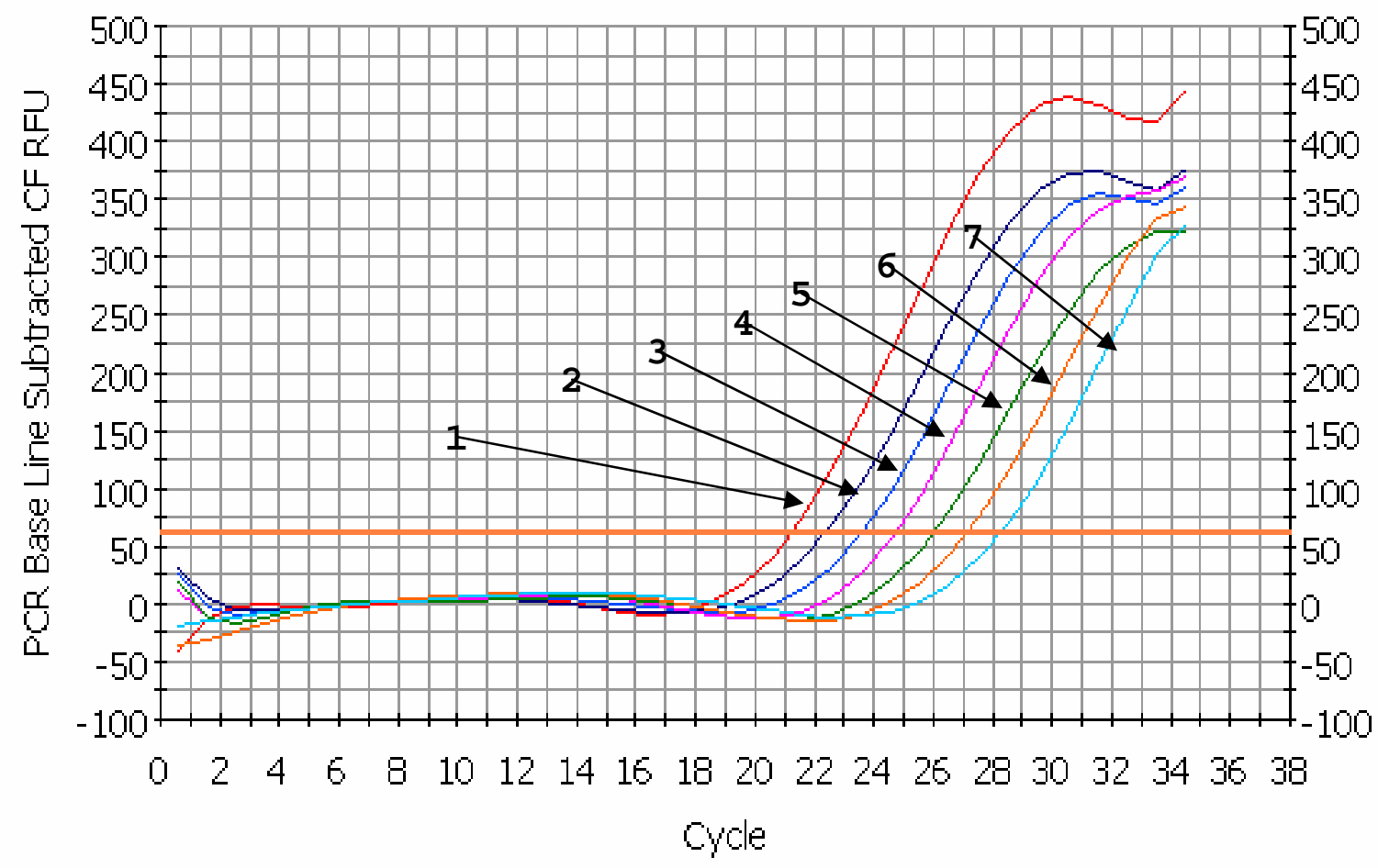

PCR Amplification vs Cycle: Data 22-Sep-03 0946 CV1.opd

Each line represents one PCR reaction. Lines 1-7 are derived from reactions containing 2 $\mu \mathrm{l}$ of template from a serial dilution starting with cDNA made with $2 \mu \mathrm{g}$ of total RNA and diluted 2-fold for each line. 
Figure 3a. LKR melt curve

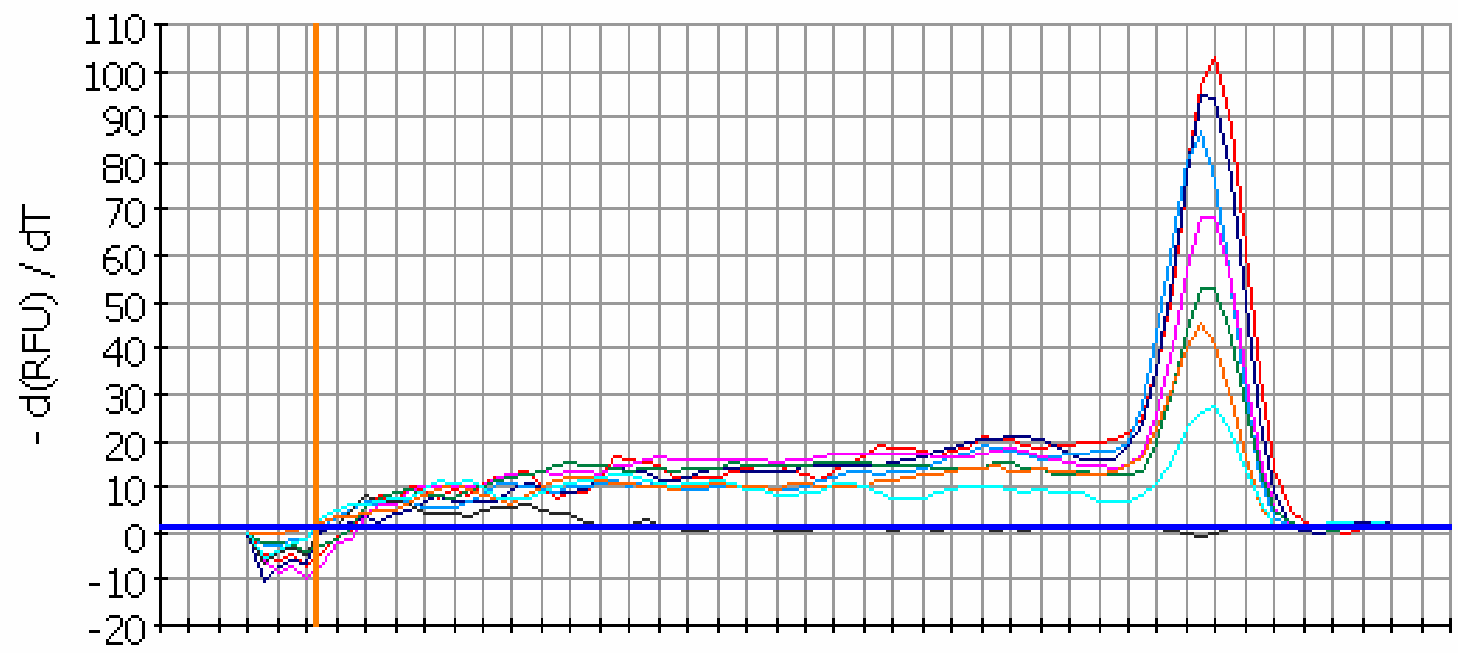

5254565860626466687072747678808284868890929496

Temperature, Celsius

Melt Peak: Data 22-Sep-03 0946 CV1.opd

Each line represents the melt curve analysis for one PCR reaction using LKR primers. The PCR reactions contained $2 \mu \mathrm{l}$ of template from a serial dilution starting with cDNA made with $2 \mu \mathrm{g}$ of total RNA and diluted 2-fold for each line. 


\section{Figure 3b. ARP Melt Curve}

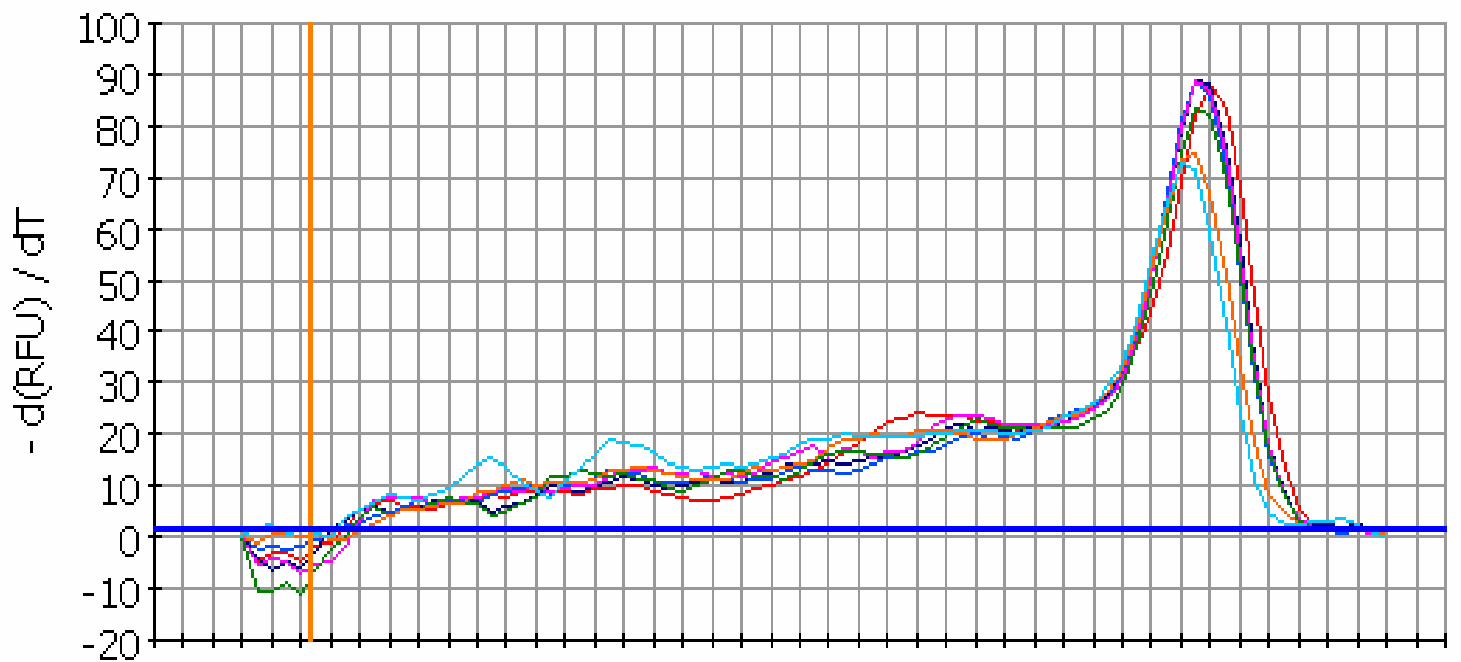

5254565860626466687072747678808284868890929496

Temperature, Celsius

Melt Peak: Data 22-Sep-03 0946 CV1.opd

Each line represents the melt curve analysis for one PCR reaction using ARP primers. The PCR reactions contained $2 \mu \mathrm{l}$ of template from a serial dilution starting with cDNA made with $2 \mu \mathrm{g}$ of total RNA and diluted 2-fold for each line. 


\section{Figure 4a. LKR regression.}

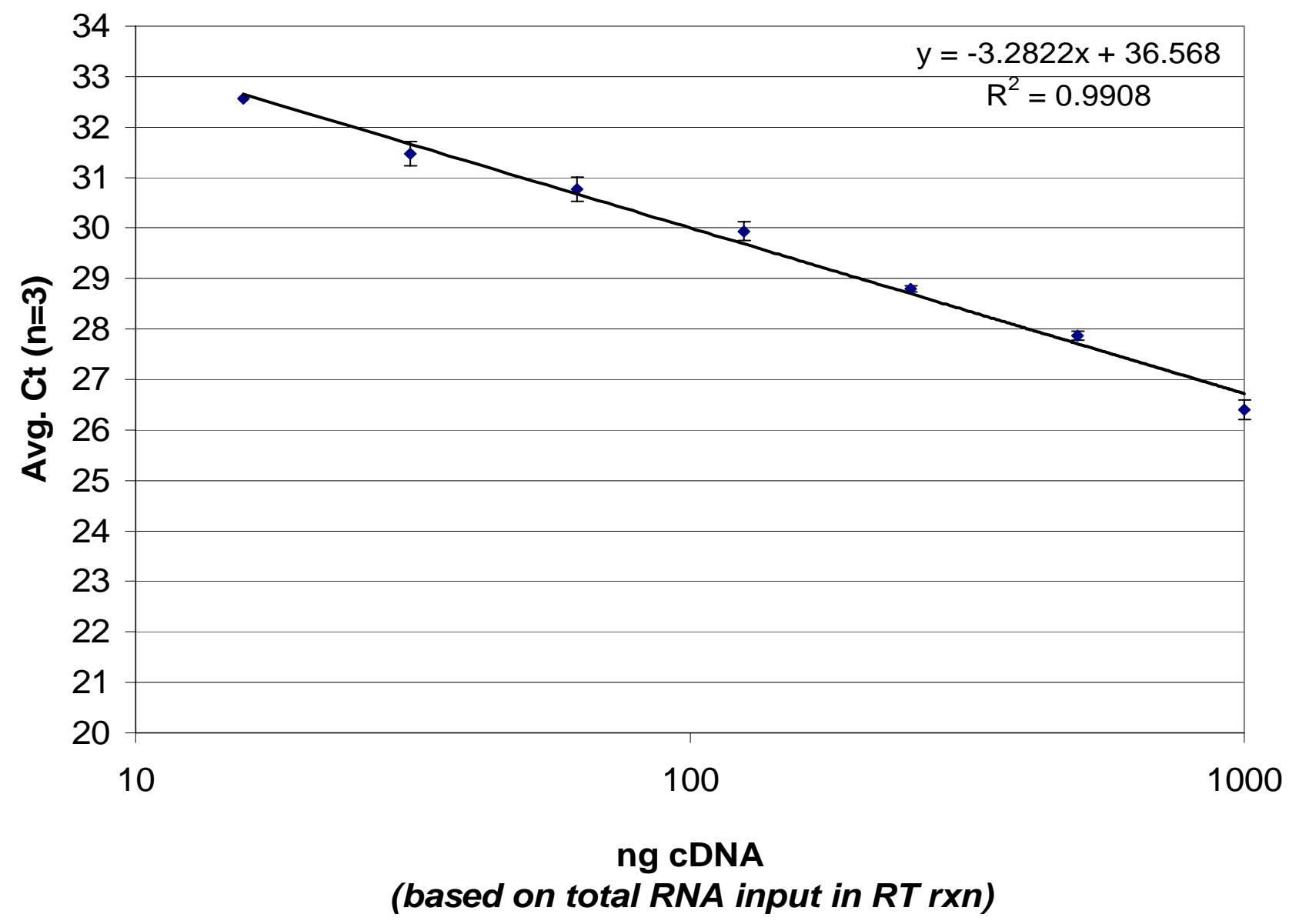

The $y$-axis is the average $C_{t}$ value for 3 PCR reactions. The $x$-axis represents serially diluted cDNA made from $2 \mu \mathrm{g}$ of total RNA. $2 \mu \mathrm{l}$ from each dilution was used as PCR template. 


\section{Figure 4b. ARP regression}

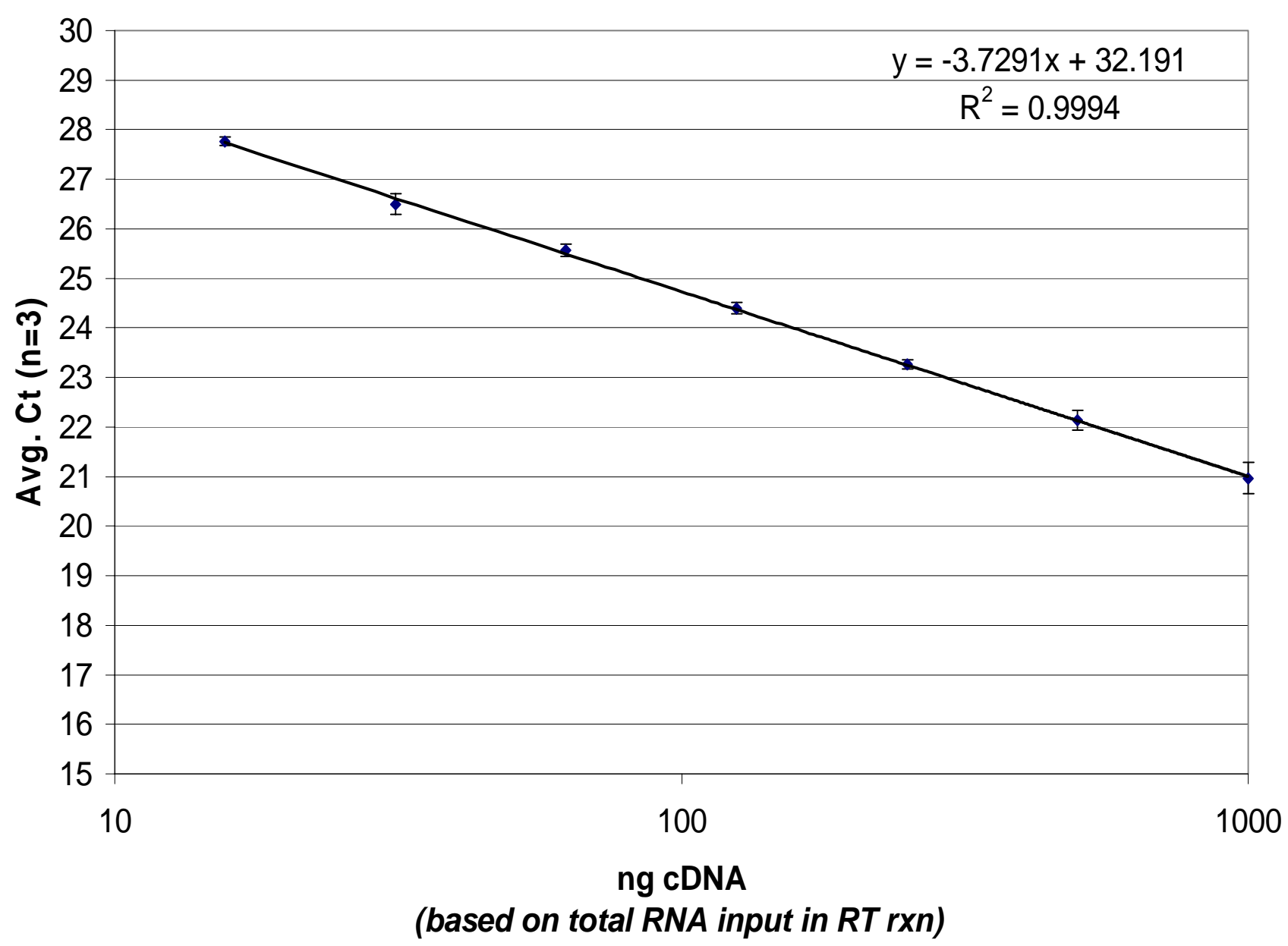

The $y$-axis is the average $C_{t}$ value for 3 PCR reactions. The $x$-axis represents serially diluted cDNA made from $2 \mu \mathrm{g}$ of total RNA. $2 \mu \mathrm{l}$ from each dilution was used as PCR template. 
Figure 5. Weight gained

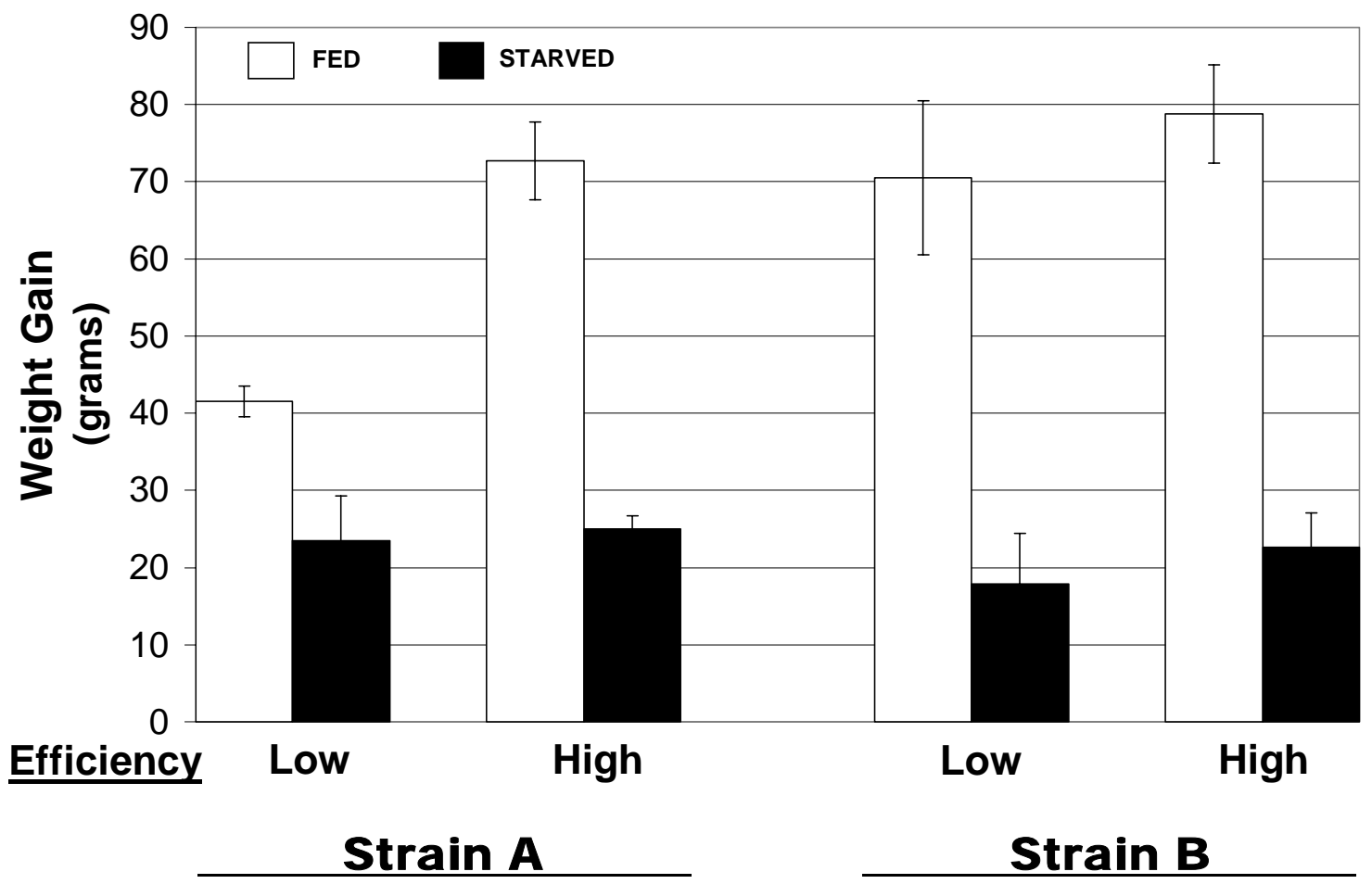

\begin{tabular}{|l|l|}
\hline Source & P-Value \\
\hline Strain & 0.1325 \\
\hline Family (Strain) & 0.0362 \\
\hline Starvation & $<0.0001$ \\
\hline Strain*Starvation & 0.0216 \\
\hline Fam*Starvation (Strain) & 0.0863 \\
\hline
\end{tabular}

Each bar represents the mean of 4 fish \pm SEM except for strain A fed, where each bar represents the mean of 3 fish. 
Figure 6. Relative liver size

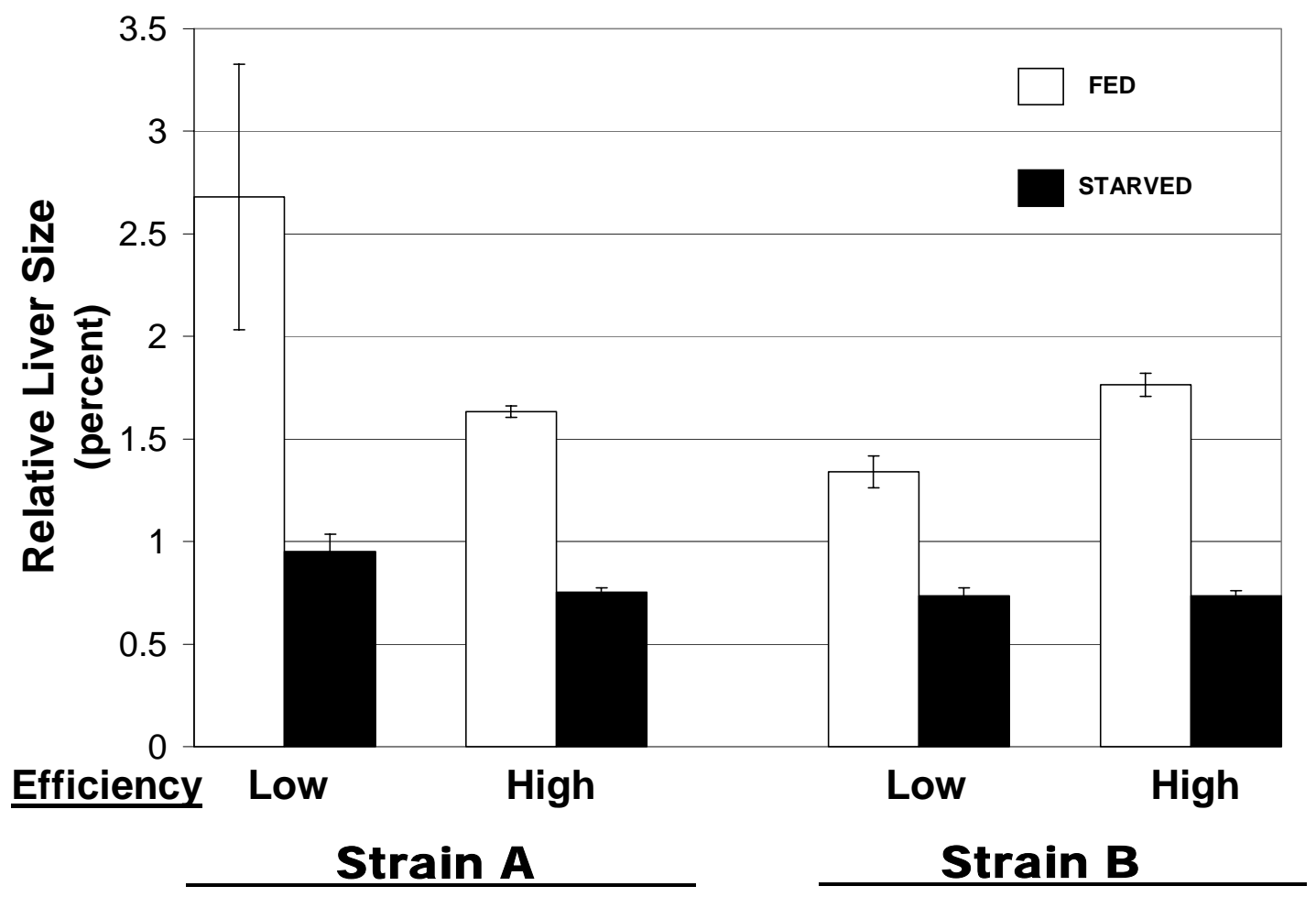

\begin{tabular}{|l|l|}
\hline Source & P-Value \\
\hline Strain & 0.0098 \\
\hline Family(Strain) & 0.00070 \\
\hline Treatment & $<0.0001$ \\
\hline Strain*Treatment & 0.0818 \\
\hline Fam*Trt (Strain) & 0.0674 \\
\hline
\end{tabular}

Relative liver size was calculated as liver weight (g)/ total body weight (g) and expressed as a percent. Each Bar represents the mean of 4 fish \pm SEM except for strain A fed, where each bar represents the mean of 3 fish. 
Figure 7. Hepatic lysine oxidation per gram liver

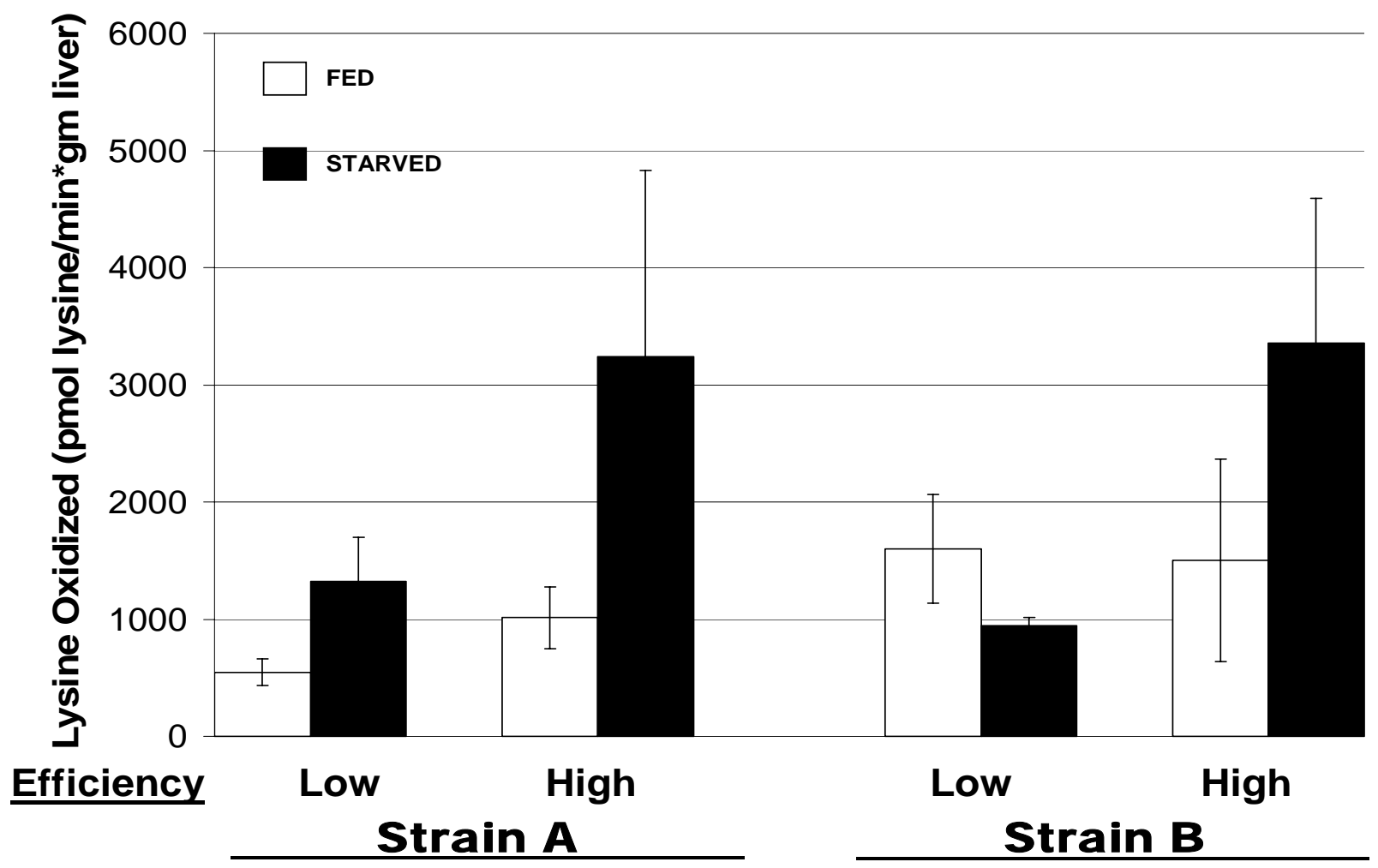

\begin{tabular}{|l|l|}
\hline Source & P-Value \\
\hline Strain & 0.6093 \\
\hline Family (Strain) & 0.1884 \\
\hline Starvation & 0.1038 \\
\hline Strain*Starvation & 0.4735 \\
\hline Fam*Starvation (Strain) & 0.2601 \\
\hline
\end{tabular}

Each Bar represents the mean of 4 fish \pm SEM except for strain A fed, where each bar represents the mean of 3 fish. 
Figure 8. Hepatic lysine oxidation per liver

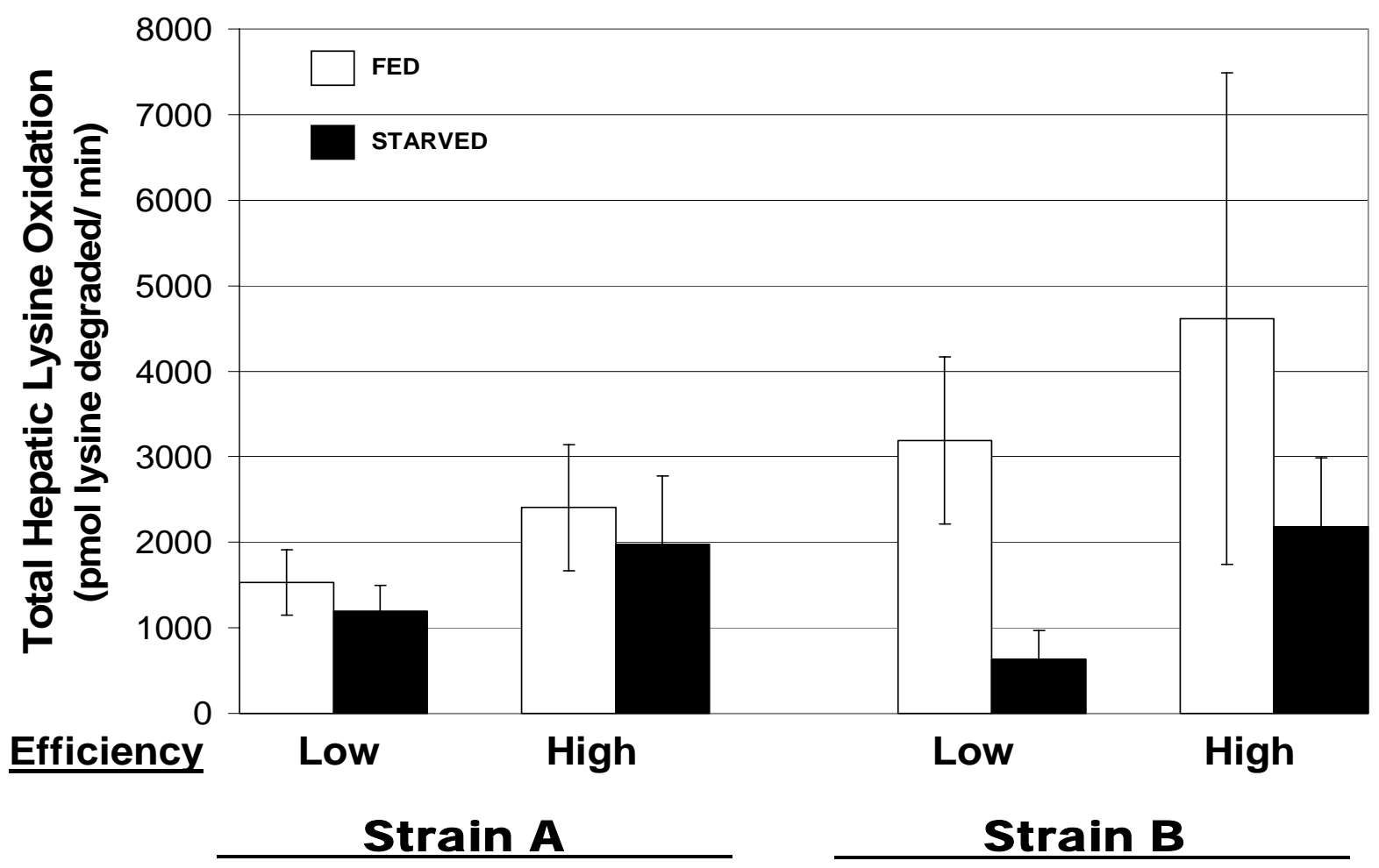

\begin{tabular}{|l|l|}
\hline Source & P-Value \\
\hline Strain & 0.3404 \\
\hline Family (Strain) & 0.4071 \\
\hline Starvation & 0.1242 \\
\hline Strain*Starvation & 0.2524 \\
\hline Fam*Starvation (Strain) & 0.9983 \\
\hline
\end{tabular}

Each bar represents the mean of 4 fish \pm SEM except for strain A fed, where each bar represents the mean of 3 fish. 
Figure 9. LKR activity per gram liver

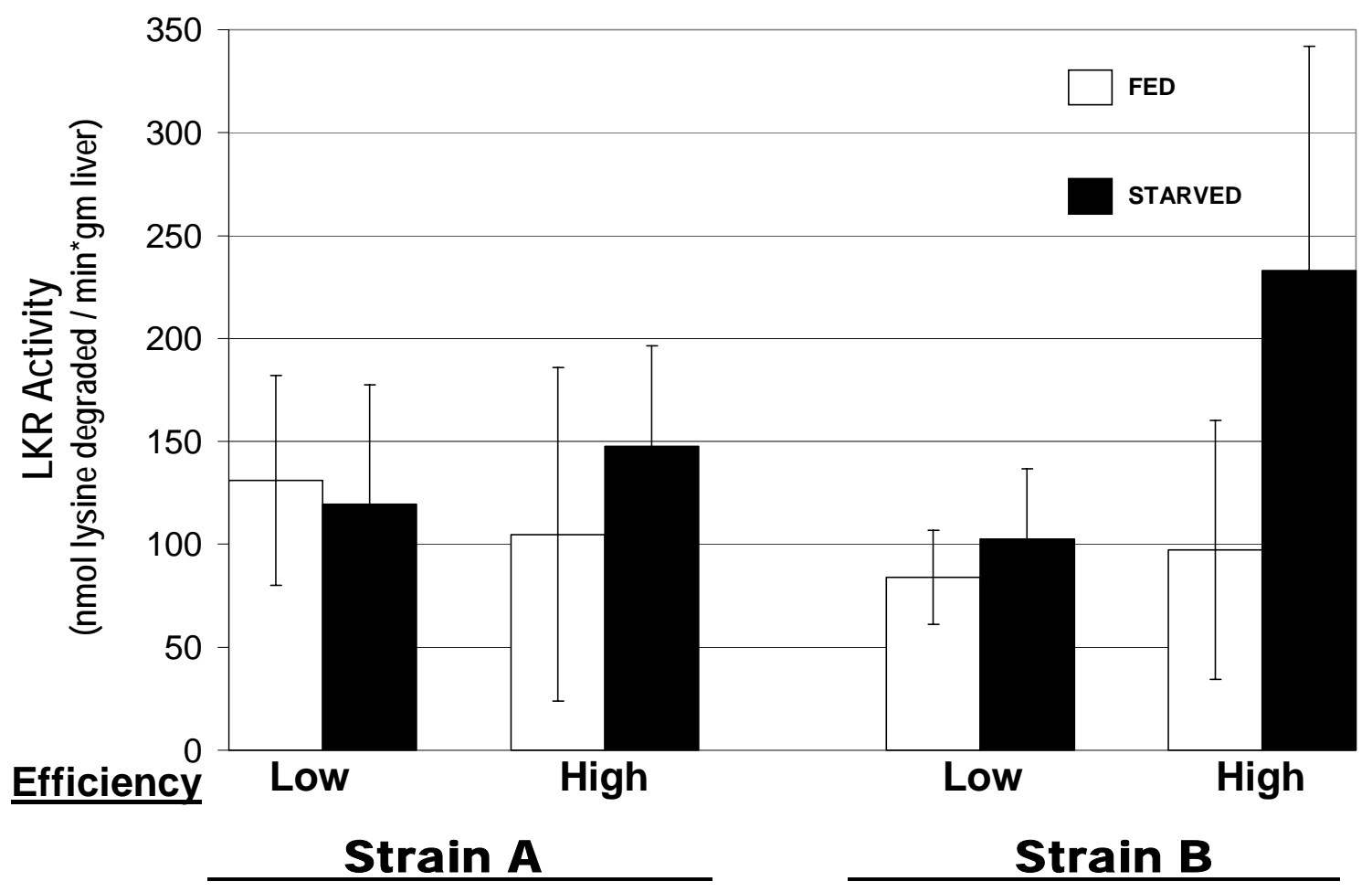

\begin{tabular}{|l|l|}
\hline Source & P-Value \\
\hline Strain & 0.9388 \\
\hline Family (Strain) & 0.5230 \\
\hline Starvation & 0.3217 \\
\hline Strain*Starvation & 0.5065 \\
\hline Fam*Starvation (Strain) & 0.5979 \\
\hline
\end{tabular}

Each bar represents the mean of 4 fish \pm SEM except for strain A fed, where each bar represents the mean of 3 fish. 
Figure 10. Hepatic LKR activity per liver

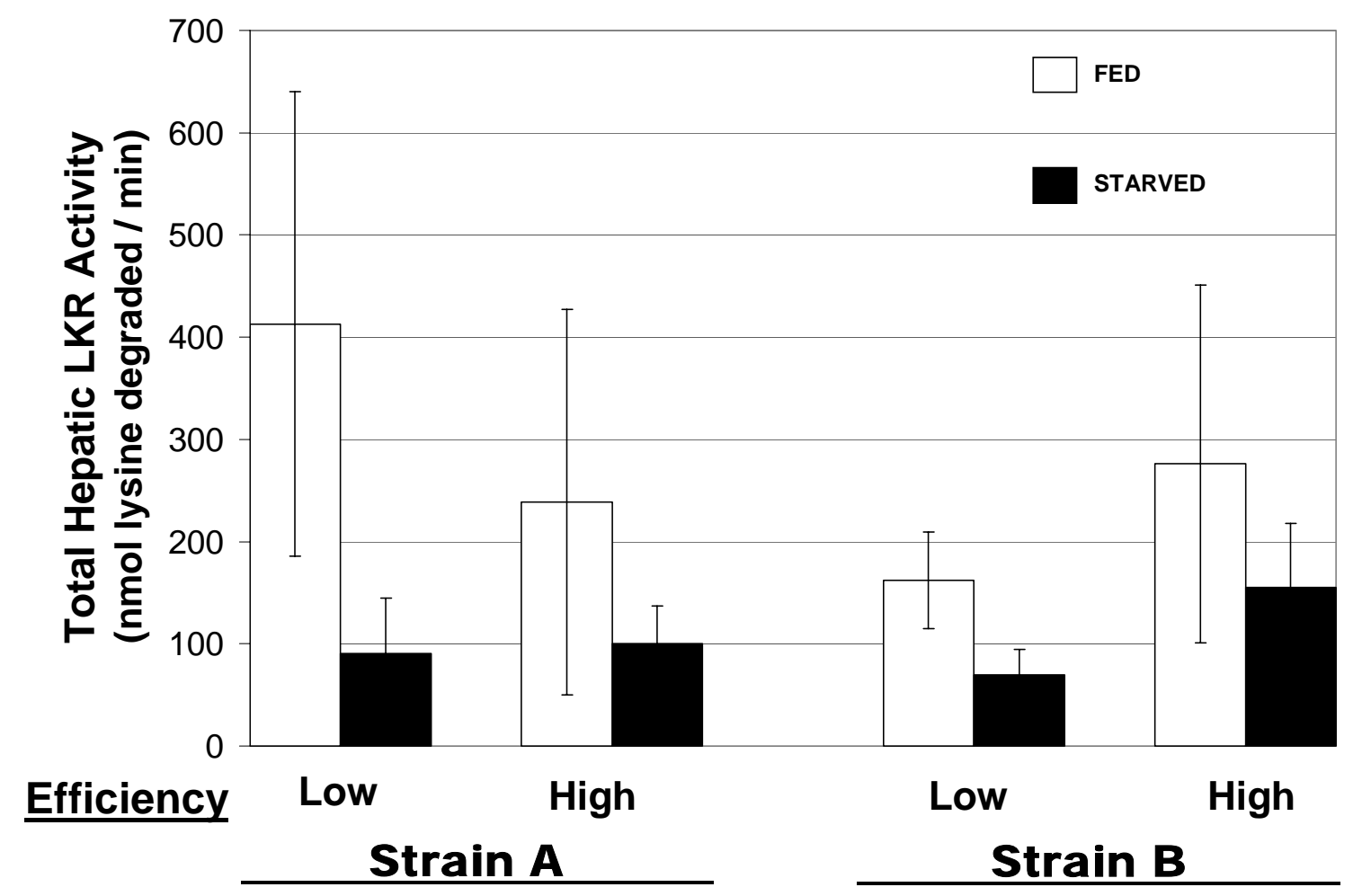

\begin{tabular}{|l|l|}
\hline Source & P-Value \\
\hline Strain & 0.5803 \\
\hline Family (Strain) & 0.5185 \\
\hline Starvation & 0.0450 \\
\hline Strain*Starvation & 0.4445 \\
\hline Fam*Starvation (Strain) & 0.7291 \\
\hline
\end{tabular}

Each bar represents the mean of 4 fish \pm SEM except for strain A fed, where each bar represents the mean of 3 fish. 


\section{Figure 11. Proportion of LKR mRNA to ARP mRNA}

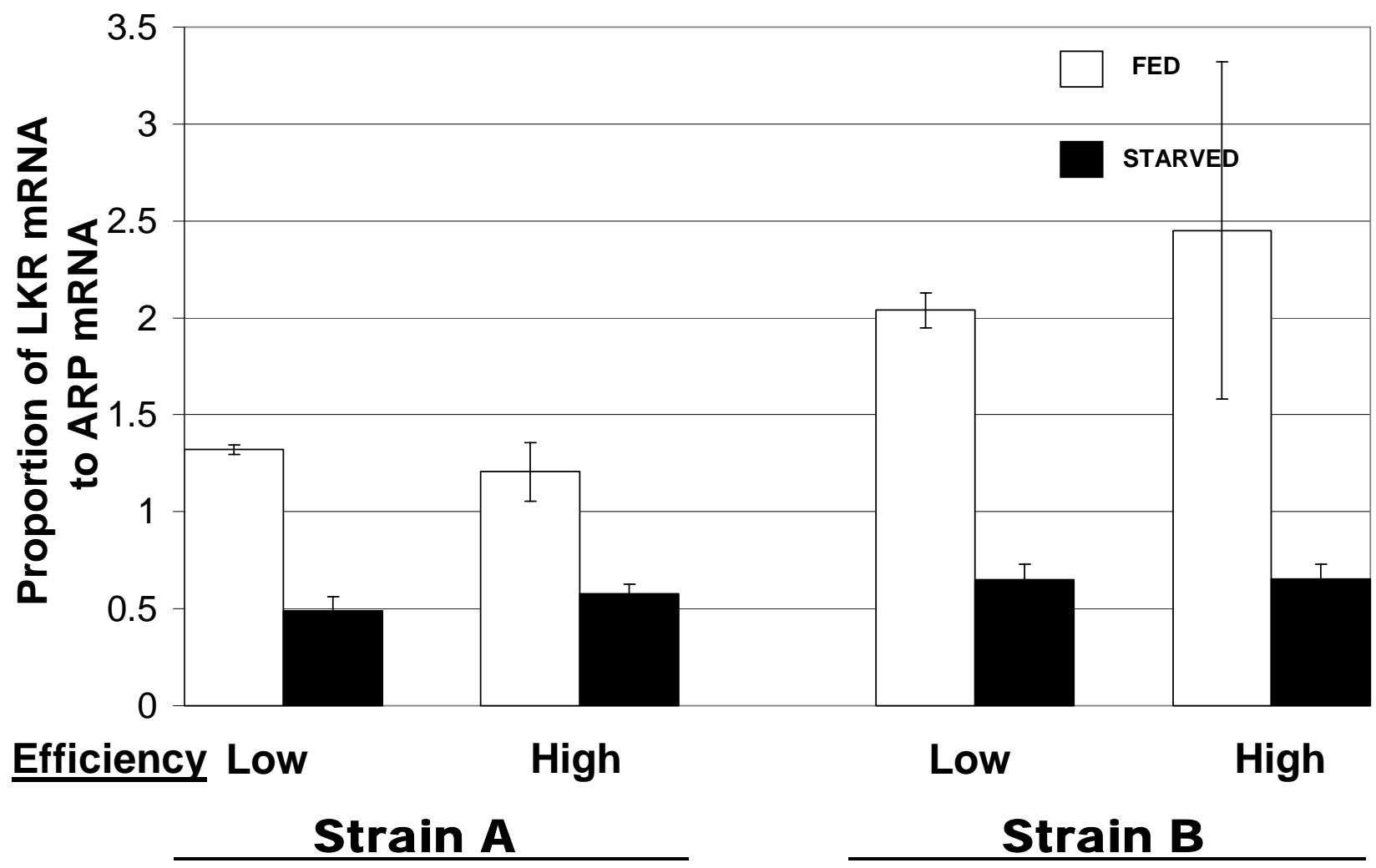

\begin{tabular}{|l|l|}
\hline Source & P-Value \\
\hline Strain & 0.0103 \\
\hline Family (strain) & 0.8048 \\
\hline Starvation & $<0.0001$ \\
\hline Strain*Starvation & 0.5267 \\
\hline Fam*Starvation(strain) & 0.5504 \\
\hline
\end{tabular}

Each bar represents the mean of 4 fish \pm SEM except for strain A fed, where each bar represents the mean of 3 fish. The y-axis ratio was calculated using Ratio $=\mathrm{E}^{\wedge}\left(\mathrm{C}_{\mathrm{t}} \mathrm{LKR}\right.$ Pool $-C_{t}$ LKR fish $) / E^{\wedge}\left(C_{t}\right.$ ARP pool $-C_{t}$ ARP fish $)$ where $E$ is the PCR efficiency. 


\section{References}

1. Ballestrazzi, R., Lanari, D., D’Agaro E., Mion A., 1994. The effect of dietary protein level and source on growth, body composition, total ammonia and reactive phosphate execretion of growing sea bass (Dicentrarchus labrax). Aquaculture 127, 197-206.

2. Barash, H., 1984. The influence of the lysine level in the diet on nitrogen excretion and on the concentration of ammonia and free amino acids in the plasma of rainbow trout (Salmo gairdneri). Nutr. Rep. Int. 29, 283-289.

3. Blemings, K.P., Crenshaw, T.D., Benevenga, N.J., 1994. Lysine $\alpha$-ketoglutarate reductase and saccharopine dehydrogenase are located only in the mitochondrial matrix in rat liver. J. Nutr. 123, 332-336.

4. Blemings, K.P., Crenshaw, T.D., Benevenga, N.J., 1998. Mitochondrial lysine uptake limits lysine oxidation in rats fed diets containing 5, 20, 60\% casein. J Nutr. 128, 2427-2434.

5. Cheng, Z.J., Hardy, R.W., Ursy, J.L., 2003a. Effects of lysine supplementation in plant protein-based diets on the performance of rainbow trout (Oncorhynchus mykiss) and apparent digestibility coefficients of nutrients. Aquaculture 215, 255 265.

6. Cheng, Z.J., Hardy, R.W., Ursy, J.L., 2003b. Plant protein ingredients with lysine supplementation reduce dietary protein level in rainbow trout (Oncorhynchus mykiss) diets, and reduce ammonia nitrogen and soluble phosphorus excretion. Aquaculture 218, 553-565.

7. Cho, C.Y., Kauchik, S.J., 1990. Nutritional energetics in fish: energy and protein utilization in rainbow trout (Salmo gairdneri). World Rev. Nutr. Diet. 61, 132-72.

8. Chu, S.W., Hegsted, D.M., 1976. Adaptive response of lysine and threonine degrading enzymes in adult rats. J. Nutr. 106, 1089-1096.

9. Emanuelsson O., Nielsen, H., Brunak, S., Heijne,G., 2002. Predicting subcellular localization of proteins based on their N-terminal amino acid sequence. J. Mol. Biol. 300, 1005-1016.

10. Epelbaum, S., McDevitt R., Falco, S.C., 1997. Lysine-ketoglutarate reductase and saccharopine dehydrogenase from Arabidopsis thaliana: nucleotide sequence and characterization. Plant Mol. Biol. 35, 735-748.

11. Foster, A.R., Scislowski, P.W.D., Harris, I., Fuller, M.F., 1993. Metabolic response of liver lysine $\alpha$-ketoglutarate reductase activity in rats fed lysine limiting or lysine excessive diets. Nutr. Res. 13, 1433-1443. 
12. Foster, G.D., Moon, T.W., 1991. Hypometabolism with fasting in the yellow perch (Perca flavescens): A study of enzymes, hepatocyte metabolism, and tissue size. Physiological Zoology 64, 259-275.

13. Gatlin D.M., Hardy, R.W., 2002. Manipulations of diets and feeding to reduce losses of nutrients in intensive aquaculture. In: Tomasso, J.R. (Ed.), Aquaculture and the environement in the United States. World Aquaculture Society, pp155165.

14. Gjedrem T., 2000. Genetic improvement of cold-water fish species. Aqua. Res. 31, 25-33.

15. Harper, A.E., 1965. Effect of variation in protein intake on enzymes of amino acid metabolism. Can. J. of Biochem. 3, 1589-1603.

16. Henryron, M., Jokumsen, A., Berg, P., Lund, I., Pedersen, P.B., Olesen, N.J., Slierendrecht, W.J., 2002. Genetic variation for growth rate, feed conversion efficiency and disease resistance exists within a farmed population of rainbow trout. Aquaculture 209, 59-76.

17. Hutzler, J., Dancis, J., 1968. Conversion of lysine to saccharopine by human tissues. Biochim. Biophys. Acta 158, 62-69.

18. Kaushik, S.J., Cowey, C.B., 1991. Dietary factors affecting nitrogen excretion by fish. In: Cowey, C.B., Cho, C.Y. (Eds.). Nutritional Strategies and aquaculture waste. Proceedings of the First International Symposium on Nutritional Strategies in Management of Aquaculture Wastes. University of Guelph, Ontario, Canadia. Blackwell Publishing, Oxford, UK, 3-19.

19. Kim, K.I., Grimshaw, T.W., Kayes, T.B., Clyde, H.A., 1992. Effect of fasting or feeding diets containing different levels of protein or amino acids on the activities of the liver amino acid-degrading enzymes and amino acid oxidation in rainbow trout (Oncorhynchus mykiss). Aquaculture 107, 89-105.

20. Kim, K.I., Kayes, T.B., Amundson, C.H., 1991. Purified diet development and reevaluation of the dietary protein requirement of fingerling rainbow trout (Oncorhynchus mykiss). Aquaculture, 96, 57-67.

21. Kinghorn, B., 1983. Genetic variation in food conversion efficiency and growth in rainbow trout. Aquaculture 32, 141-155.

22. McCarthy, I.D., Houlihan, D.F., Carter, C.G., 1994. Invididual variation in protein turnover and growth efficiency in rainbow trout, Oncorhynchus mykiss (Walbaum). Proc. R. Soc. Lond. B. 257, 141-147. 
23. Medale, F., Brauge, C., Vallee F., Kaushik S.J., 1995. Effects of dietary protein/energy ratio, ration size, dietary energy source and water temperature on nitrogen excretion in rainbow trout. Wat. Sci. Tech. 31, 185-194.

24. Miron, D., Ben-Yaacov, S., Karchi, H., GaliliG., 1997. In vitro dephosporylation inhibits the activity of soybean lysine-ketoglutarate reductase in a lysine-regulated manner. The Plant J. 12, 1453-1458.

25. Papes F., Kemper, E.D., Cord-Neto, G., Langone, F., Arruda P., 1999. Lysine degradation through the saccharopine pathway in mammals: involvement of both bifunctional and monofunctional lysine degrading enzymes in mouse. Biochem. J. 344, 555-563.

26. Pfaffl, Michael W., 2001 A new mathematical model for relative quantification in real-time RT-PCR. Nucl. Acids. Res. 29, 2002-2007.

27. Pierce, A.L., Dickey, J.T., Larsen, D.A., Fukada, H., Swanson, P., Dickhoff, W.W., 2004. A quantitative real-time RT-PCR assay for salmon IGF-I mRNA, and its application in the study of GH regulation of IGF-I gene expression in primary culture of salmon heptocytes. Gen. Comp. Endrocrinol. 135, 401-411.

28. Rodehutscord, M., Mandel, S., Pfeffer, E., 1994. Reduced protein content and use of wheat gluten in diets for rainbow trout: effects on water loading with $\mathrm{N}$ and $\mathrm{P}$. J. Appl. Ichthyol. 10, 271-273.

29. Shang, Y.C., Tomasso, J., 1990. Aquaculture Economic Analysis: An Introduction. The World Aquaculture Society, Baton Rouge.

30. Silverstein, J.T., 2004. Using genetic variation to understand control of feed intake in fish. Fish Physiol. Biochem. 27, 173-178.

31. Torres, N., Martinez, L., Aleman, G., Bourges, H., Tovar, A.R., 1998. Histidase expression is regulated by dietary protein at the pretranslational level in rat liver. J. Nutr. $128,818-824$.

32. Viola, S., Lahav, E., 1991. Effects of lysine supplementation in practical carp feeds on total protein sparing and reduction in pollution. Isr. J. Aquac.-Bamidgen $43,112-118$.

33. Viola, S., Lahav, E., Angeoni, H., 1992. Reduction of feed protein levels and of nitrogenous $\mathrm{N}$-excretions by lysine supplementation in intensive carp culture. Aquat. Living Resour. 5, 277-285.

34. Wang, S.H., Crosby, L.O., Nesheim, M.C., 1973. Effect of dietary excesses of lysine and arginine on the degradation of lysine by chicks. J. Nutr. 103, 384-391. 
35. Walton, M.J., Cowey, C.B., Adron, J.W., 1984. The effect of dietary lysine levels on growth and metabolism of rainbow trout (Salmo gairdneri). Brit. J. Nutr. 52, $115-122$. 


\section{Appendix I: Library screening for lysine $\alpha$-ketoglutarate reductase cDNA}

\section{Introduction}

Improving the efficiency of lysine use for protein synthesis can benefit the poultry industry by reducing feed costs and reducing the amount of nitrogen flow into the environment. One way to increase the utilization of lysine is to decrease the amount of free lysine degraded. However, lysine degradation has been little studied in chickens.

LKR is the presumed major pathway for lysine degradation in chickens. LKR activity has been found in most chicken tissues (Managi et al., submitted). Similar to other animals, increases in LKR activity parallel increases in dietary lysine (Wang and Nesheim, 1973). Moreover, Wang and Nesheim (1973) reported an interaction between LKR activity and genotype but a specific regulatory mechanism for LKR activity is unknown.

Since LKR may be responsible for a majority of lysine degradation in the chicken, strategies aimed at down regulating LKR activity may increase lysine use for protein synthesis. Similar strategies have been attempted in plants. For example, an Arabidopsis knockout mutant for LKR was shown to have elevated free lysine pools, as well as, to have greater incorporation of lysine into protein, in Arabidopsis seeds (Zhu et al., 2001). However, for animals, a total knockout of LKR activity is undesirable. Thus, specific information regarding the regulation of LKR activity is critical for developing genetic strategies aimed at down regulating LKR activity. Obtaining a LKR cDNA clone would be an essential first step for any strategy.

Possession of a LKR cDNA clone could provide important information about the regulation of LKR activity. First, sequence analysis of LKR mRNA could reveal 
important regions for post-transcriptional and translational regulation. Second, the inferred protein structure could be assessed for phosphorylation and substrate binding sites. Third, the LKR clone could be used to generate protein for the production of antibodies thus, providing a tool for protein studies in the future. Finally, the effects of base pair mutations on post-transcription, translation and protein function could be examined.

The goal of this project was to obtain a full length LKR cDNA using several strategies. First, a pre-made chicken heart cDNA phage library was screened. Second, a chicken liver cDNA plasmid library was constructed and screened using standard hybridization techniques. Third, a partial EST clone from a chicken heart was obtained elsewhere and 5'RACE attempted. Fourth, a nested PCR approach, using the chicken liver cDNA library for template, was used to try and isolate the 5'and 3' ends of the LKR message. The two cDNA ends would then be ligated together for form a complete cDNA. All strategies failed to produce a full length LKR cDNA. 


\section{Materials and Methods}

\section{Screening Chicken Heart Library}

\section{Chicken Heart Phage Library}

A 7 week old male broiler chicken heart cDNA library in the lambda ZAP vector was purchased from Stratagene (La Jolla, CA). This library was amplified and used for screening. The library titer was $1.0 \times 10^{5} \mathrm{pfu} / \mathrm{ml}$.

\section{Primers}

Primers were designed to mouse LKR cDNA. Using chicken liver cDNA as template, a $400 \mathrm{bp}$ product was produced. The PCR product was sequenced and determined to be LKR. The forward primer and reverse primer annealed to nucleotides 1461 and 1848 on the mouse cDNA sequence. The $5^{\prime} \rightarrow 3^{\prime}$ sequence for the forward and reverse primers are TTTGGTCCTTGGGTCTGGCTATG and TGCCAACATGTGATCGAGACCAG, respectively.

\section{PCR Screening of Library}

XL1-MRF' cells were prepared according to Stratagene protocol. Five hundred $\mu 1$ of XL1-MRF' cells were added to $500 \mu \mathrm{l}$ of SM buffer (SM buffer per liter contains: $5.8 \mathrm{~g}$ $\mathrm{NaCl}, 2.0 \mathrm{MgSO}_{4} * \mathrm{H} 2 \mathrm{O}, 50 \mathrm{ml}$ of $1 \mathrm{M}$ Tris- $\mathrm{HCl} \mathrm{pH} 7.5,5.0 \mathrm{ml}$ of $2 \%$ (w/v) gelatin and 20 $\mu l$ of chloroform). One $\mathrm{ml}$ of library was added to the cells and incubated at room temperature for 20 minutes. Twenty $\mathrm{ml}$ of $\mathrm{LB}$ broth and $200 \mu \mathrm{l}$ of $1 \mathrm{M} \mathrm{MgSO}_{4}$ were 
added to infected cells, then $100 \mu \mathrm{l}$ per well were dispensed into 96 well U-bottom plate. The plate was sealed with parafilm and incubated at $37^{\circ} \mathrm{C}$ for 6 hours with shaking. Ten $\mu l$ from each well was pooled across rows and columns. Ten $\mu$ from each pool was diluted with $10 \mu$ of water. LKR specific primers $(1461,1848)$ and $2 \mu 1$ of the diluted pool were used for PCR $\left(5 \min 94^{\circ} \mathrm{C} \rightarrow 1 \min 55.7^{\circ} \mathrm{C} \rightarrow 1: 30 \min 72^{\circ} \mathrm{C}\right)$. Individual wells, from pools identified as positive for LKR, were diluted ( $5 \mu 1$ culture:5 $\mu 1$ water) and $2 \mu 1$ used for another round of PCR. Two individual wells were identified as positive for LKR. The titer of wells was approximately $1 \times 10^{7} \mathrm{pfu} / \mathrm{ml}$. Culture from each well was used to inoculate prepared XL1- MRF' cells and another round of PCR screening using a 96 well plate was performed. Several pools produced positive bands. PCR of individual wells showed 3 wells positive for LKR. The culture from these 3 wells was used for nucleic acid hybridization screening.

\section{Nucleic Acid Hybridization}

The screening procedure was conducted according to the Stratagene protocol. XL1MRF' cells were prepared, inoculated with culture from the wells identified as having LKR and incubated for 15 minutes. Six hundred $\mu \mathrm{l}$ of inoculated cells were plated onto top agar and incubated overnight at $37^{\circ} \mathrm{C}$. A total of 15 plates with a 88 -mm diameter were prepared. 


\section{Plaque Lifting}

The denaturing solution $(1.5 \mathrm{M} \mathrm{NaCl}, 0.5 \mathrm{M} \mathrm{NaOH})$, neutralizing solution $(1.5 \mathrm{M} \mathrm{NaCl}$, $0.5 \mathrm{M}$ Tris- $\mathrm{Cl} \mathrm{pH}$ 8) and rinsing solution (0.2M Tris- $\mathrm{Cl} \mathrm{pH} 7.5)$ were prepared. Hybond$\mathrm{N}+$ nylon transfer membranes with a 45 micron pore size (Amersham, Pisscataway, NJ) were used to lift plaques. Membranes were placed on chilled plates for 2 minutes. A hypodermic needle with India ink was used to preserve orientation of membrane on plate. Whatman 3MM paper was saturated with the denaturing, neutralizing or rinsing solution. Each membrane was placed DNA side up on saturated Whatman 3MM paper for the following times: 2 minutes denaturing, 5 minutes neutralizing, and 30 seconds rinsing. The membranes were air dried, DNA side up. DNA was crosslinked to membranes at 120,000 mJ of UV energy for 30 seconds in a UVC-515 Ultravioloet Multilinker (UltraLum Inc., Carson, CA). Membranes were interleaved between chromotography paper and stored in plastic bags until hybridization.

\section{Prehybridization}

Prehybridization buffer (6x saline sodium citrate (SSC), 5x Denhardt's reagent (1\% Ficoll 400, 1\% polyvinylpyrrilidone, $1 \%$ bovine serum albumin), 0.5\% sodium dodecyl sulfate (SDS), 50\% formamide, $100 \mu \mathrm{g} / \mathrm{ml}$ denatured sheared salmon sperm (Ambion, Austin, TX)) was prepared. Membranes were saturated with prehybrization buffer, then placed in hybridization tubes containing prehybridization buffer and rotated in a hybridization oven at $42^{\circ} \mathrm{C}$ for 2 hours. 


\section{Probe}

A clone containing the 400bp PCR product was digested with Eco RI (Promega Corp, Madison, WI). Products were seperated on $1.5 \%$ agarose gel. The $400 \mathrm{bp}$ band was gel purified using a DNA Freeze-N-Squeeze kit ( Biorad, Hercules, CA). The DNA was labeled using Ready to Go DNA labeling beads (Amersham, Pisscataway, NJ). $50 \mu \mathrm{Ci}$ of

$\alpha-{ }^{32} \mathrm{P}$ dCTP was used. The probe was purified over a Probequant G-50 Microcolumn (Amersham, Piscataway, $\mathrm{NJ}$ ) column to get rid of unincorporated ${ }^{32} \mathrm{P}$.

\section{Hybridization}

Hybridization buffer $(6 \times \mathrm{SSC}, 0.5 \% \mathrm{SDS}, 50 \%$ formamide, $100 \mu \mathrm{g} / \mathrm{ml}$ denatured salmon sperm DNA) was prepared. Ten $\mu$ of probe was added per $10 \mathrm{ml}$ of hybridization buffer used. Prehybridization buffer was removed from the hybridization tubes containing the membranes. Hybridization buffer was added and the membranes were incubated overnight in a hybridization oven at $42^{\circ} \mathrm{C}$ while rotating.

\section{Washing}

Membranes were washed in the hybridization oven while rotating with 3 solutions. Washing solution \#1 (2x SSC, $0.1 \%$ SDS) was used at room temperature for 10 minutes. Washing solution \#2 (0.5x SSC, $0.1 \%$ SDS $)$ was used for 20 minutes at $55^{\circ} \mathrm{C}$. Washing solution \#3 (0.1x SSC, $0.1 \%$ SDS) was used for 20 minutes at $65^{\circ} \mathrm{C}$. Membranes were removed from tubes and air dried briefly on chromatography paper. 


\section{Film Exposure}

Membranes were placed DNA side down to BioMax MS scientific imaging film (Kodak, Rochester, NY), exposed overnight in a cassette with an intensifying screen at $-80^{\circ} \mathrm{C}$ and developed the following morning.

\section{Reagents and Chemicals}

$\alpha-{ }^{32} \mathrm{P}-\mathrm{dCTP}$ was from American Radiolabel Chemicals Inc. (St. Louis, MO). Biosafe-II scintillation fluid was from Research Products Inc. (Mount Prospect, IL). Gene specific primers were synthesized by Invitrogen (Carlsbad, CA). All chemicals not listed in the material and methods were from Sigma-Aldrich (St. Louis, MO).

\section{Chicken Liver Library Screening}

\section{Library Construction}

A chicken liver cDNA library was made using the Superscript Plasmid System with Gateway technology from Invitrogen (Carlsbad, CA). Total RNA was isolated from the liver of a 3 week old Ross x Ross chicken. Prior to library construction, RT-PCR was used to confirm the presence of LKR in the extracted RNA. mRNA was purified from $900 \mu \mathrm{g}$ of total RNA using a PolytractA mRNA isolation kit (Promega Corp., Madison, WI). To concentrate the mRNA, purified mRNA was dried in a speed vaccum on low heat. The pellet was resuspended in $10 \mu \mathrm{l}$ of nuclease free water. The first library was constructed following Promega's protocol. A second library was constructed using a 
slightly modified protocol. Pellet paint (Novagen, Darmstadt, Germany) was used in each precipitation step to ensure the precipated DNA was not lost. $\alpha-{ }^{32} \mathrm{P}-\mathrm{dCTP}$ was not used in the first cDNA strand synthesis, since it may reduce reverse transcription efficiency. For the transformation both chemically competent and ElectroMAX DH10B electrocompetent cells (Invitrogen, Carlsbad, CA) were used with $1 \mu$ l of ligation reaction. The titer for the transformation using the chemically competent cells was $10^{4}$ $\mathrm{cfu} / \mathrm{ml}$. The titer for the transformation reaction using electrocompetent cells was $10^{5}$ $\mathrm{cfu} / \mathrm{ml}$ therefore, the electrocompetent cells were transformed with the remaining ligation reaction. The final library contained approximately $10^{6} \mathrm{cfu}$. To check the size of the cDNA inserts, ten $1 \mu 1$ aliquots of library were digested with Mlu I restriction enzyme (Promega Corp., Madison, WI). The size of the fragments ranged from 500bp-3000bp.

\section{Library Screening}

The library was plated on nylon membranes atop $150 \mathrm{~mm} \mathrm{LB}$ (per liter: $10 \mathrm{~g} \mathrm{NaCl}, 10 \mathrm{~g}$ bactotryptone, $5 \mathrm{~g}$ yeast extract) plates containing $100 \mu \mathrm{g} / \mathrm{ml}$ ampicillian (amp) and incubated overnight. Replicas of the nylon membranes were made. Bacterial cells were lysed (Sambrooke and Russell. p1.132-1.142). To fix the DNA, the membranes were baked at $80^{\circ} \mathrm{C}$ in a hybridization oven for approximately 2 hours. Nucleic acid hybridization was conducted as previously described.

\section{Film Exposure}

The membranes were exposed to BioMax MS imaging film (Kodak, Rochester, NY) and placed in cassettes. The cassettes were kept at room temperature for approximately 3 
days. An intensifying screen was not used with the membranes. The film was developed using Kodak processing chemicals, GBX Fixer and Developer (Kodak, Rochester, NY).

\section{5'Rapid Amplification of cDNA ends and chicken EST clone}

\section{Chicken EST Clone}

A search of TIGR (The Institute for Genomic Research) database uncovered an EST (Expressed Sequence Tag) clone from a chicken (layer) heart library that contained LKR. Approximately $568 \mathrm{bp}$ of the clone were sequenced, which corresponded to nucleotides 1732 and 2300 on the mouse cDNA LKR. Assuming the clone contained the remaining 3' end, 5' Rapid Amplification of cDNA Ends (RACE) could provide the missing 5' end. The 5' cDNA end and 3' cDNA end could be ligated together for a complete LKR cDNA. The clone was obtained from the United Kingdom Chicken Consortium (Cambrige, UK). The entire clone was sequenced and found to contain only a $686 \mathrm{bp}$ cDNA insert. Efforts to obtain the 5' cDNA end were already in process prior to receiving the clone.

\section{5' RACE Procedure}

RNA Ligase Mediated Rapid Amplification of cDNA ends (RLM-RACE) kit from Ambion (Austin, TX) was used for 5' RACE. Total heart RNA was isolated from $80 \mathrm{wk}$ old white leghorn layers. RNA was extracted using TRIZOL (Ambion Inc., Austin, TX) followed by two washes with a 125:24:1 mixture of phenol acid, chloroform and isoamyl 
alcohol (Ambion, Inc., Austin, TX) and two washes with a 25: 24:1 mixture of phenol, chloroform and isoamyl alcohol (Ambion, Inc., Austin, TX). RNA quality was assessed using $\mathrm{OD}_{260} / \mathrm{OD}_{280} \mathrm{~nm}$ absorption ratio and visualized on a $1.5 \%$ agarose gel. RT-PCR was performed using LKR specific primers to confirm the presense of LKR mRNA in extracted RNA. 5'RACE was executed according to the manufactuer's protocol.

To amplify LKR from the cDNA, an outer PCR then inner (nested) PCR was performed. The reverse outer and inner PCR primer annealed at the 2003 and 1935 nucleotide on mouse LKR cDNA. A second set of reverse outer and inner PCR primers annealed at the 1848 and 1750 nucleotide on mouse LKR cDNA. The forward primers were provided in the kit and annealed to the 5' adaptor attached to the 5'end of the mRNA. The PCR cycling was $45 \mathrm{sec} .95^{\circ} \mathrm{C} \rightarrow 45 \mathrm{sec}$. annealing temp. $\rightarrow 72^{\circ} \mathrm{C} 3 \mathrm{~min}$. Ambion's Super Taq Plus with proofreading activity was used for all subsequent PCR. A $1.0 \%$ agarose gel was used to visualize inner PCR products.

\section{PCR approach for obtaining LKR from library}

\section{Theory}

The 5'and 3' cDNA ends of LKR could be isolated from the library using nested PCR with a vector specific primer. cDNA was directionally inserted for library construction, therefore SP6 and T7 primers were used to obtain the 5' and 3' cDNA end, respectively. The first PCR would enrich single stranded LKR templates from the library by only using one gene specific reverse primer for isolation of the 5 ' end or a gene specific forward 
primer for isolation of the 3' end. For 5' end isolation, the nested PCR would use a gene specific reverse primer, more 5' of where the first reverse primer annealed, and SP6. For 3' end isolation, the nested PCR would use a nested forward primer and T7. From this procedure, two overlapping pieces of LKR cDNA could be T/A cloned from PCR products. The pieces could then be ligated together to generate a full length LKR cDNA clone.

\section{Procedure}

For isolation of the 5' LKR cDNA, two primer combinations were used. The first combination annealed at 2003 and 1848 nucleotides. The second primer combination annealed at 1848 and 1750 . Ten $1-\mu l$ aliquots of chicken liver cDNA library were used in ten separate PCR reactions with only a reverse LKR specific primer to enrich for LKR. Either reverse primer 2003 or 1848 were used for a total of 20 PCR reactions. The PCR cycling was $30 \mathrm{sec} .94^{\circ} \mathrm{C} \rightarrow 30 \mathrm{sec}$. annealing temperature $\rightarrow 3 \mathrm{~min} .72^{\circ} \mathrm{C}$ for 50 cycles. In a nested PCR, the vector primer SP6 and a LKR specific primer 1848 or $1750 \mathrm{nt}$ were used with $2 \mu \mathrm{l}$ of PCR products for template. For isolation of the 3' LKR cDNA the same procedure was used with forward primers the annealed to 1461 and 1750 nucleotides. Ambion's Super Taq Plus was used for all PCR. PCR products were analyzed on a $1.0 \%$ agarose gel. All PCR products were cloned using TOPO TA cloning (Invitrogen, Carlsbad, CA). 


\section{Results}

\section{Chicken Phage Library Screening}

Seventeen positive plaques were identified from the first hybridization screening and prepared for a secondary screening. The membranes were orientated with the plates and the areas matching the corresponding positive signal were cut out with an inverted pipette tip. The phage were separated from the agarose by vortexing in $1 \mathrm{ml}$ of SM buffer. From this preparation, the phage were diluted 1:50. XL1-MRF' cells were infected with the phage, plated in top agar and grown overnight at $37^{\circ} \mathrm{C}$. The following day, no plaques were visible on the plates. Two possible explanations for no growth are 1) the XL1-MRF' cells used were no longer viable or 2) the phage were overdiluted in the SM buffer.

New XL1-MRF' cells were grown up from the glycerol stock. Using the same 1:50 dilutions for infection, no plaques were visible with the fresh cells. To examine the possibility that the phage were overdiluted, the MRF' cells were infected with $1 \mu \mathrm{l}$ of phage from a 1:10 dilution and $1 \mu \mathrm{l}$ directly from the plaque picks. The next day no plaques were visible on the plate. These results suggest that the plaques (phage) may have been too diluted in the SM buffer. Therefore the phage were amplified by adding XL1-MRF' cells and LB broth, then grown for $6 \mathrm{hrs.} \mathrm{Dilutions} \mathrm{of} \mathrm{the} \mathrm{culture} \mathrm{were} \mathrm{used}$ to infect fresh XL1-MRF' cells and plated in top agar. The titer was high therefore, the phage from the original picked plaques were most likely over diluted in $1 \mathrm{ml}$ of SM buffer. A secondary screening was performed on these plates. No positive plaques were found. 
Perhaps, the 17 plaques identified in the first screening were false positives or the hybridization procedure failed. To confirm the presence of LKR on the plates, two PCR reactions were performed. The first PCR used the bacterial culture from the secondary screening for template. For the second PCR, the plates used in the secondary screening were soaked in SM buffer while oscillating and the $2 \mu \mathrm{l}$ of SM buffer were used as template for PCR. The results for both PCR reactions were negative for LKR suggesting LKR was not on the plates nor in one of the 17 plaques identified in the first screening.

A PCR screen of the library was attempted two more times but was unsuccessful. To determine if LKR was present in the library, a 6-fold serial dilution of the library was used as template for PCR. The results of the PCR were negative. Therefore, LKR may not be represented in the library. This is possible since the library was amplified from an existing library and the quality of the library can decrease upon amplification. However, it is possible that the library contains a LKR cDNA that is incomplete at the 5' end. LKR is a large mRNA of approximately $3.3 \mathrm{~kb}$. The forward primer anneals at nucleotide 1461 of the mouse cDNA, thus that portion of the cDNA may be absent from the library and hence these primers would be unable to find LKR. Finally, a 5 minute denaturing step at $95^{\circ} \mathrm{C}$ at the beginning of the PCR may not have been long enough to burst open the phage making the DNA available for priming, therefore, $\beta$-actin primers (Promega Corp., Madison, WI) were used in PCR with the same 6-fold library dilution as template. The 1:1000 and 1:10,000 dilutions did not yield a product, while the 1:10,1:100 and 1 or $2 \mu 1$ of library were all positive for $\beta$-actin. Thus, PCR should have identified LKR provided the clone contained the 5 'end with the forward primer sequence. 


\section{Results}

\section{Chick Liver cDNA Library Screening}

The library was screened three times using approximately twenty 150 -mm diameter Petri dishes for each screening. The number of the colonies on the plate was less than predicted by the library titer. Approximately, 500-1000 colonies were observed on a plate, when 2000 were expected. The library was titered again and was still $10^{5} / \mathrm{ml}$. Perhaps, plating the library on the membrane affected its growth efficiency, although this seems unlikely. The plates used for the screening were always fresh. For the third screening, the library was plated directly on the LB surface. Approximately 1000 colonies were on each plate. Overall, less than 100,000 colonies were screened.

The results from the first library screening were negative. The positive control worked, therefore the hybridization was successful. For the second screening, 14 areas were identified on the plates as presumptive positives for LKR. Using a toothpick, the positive areas were scraped and grown in $5 \mathrm{ml}$ of LB for 5-6 hours. Two $\mu$ l of the bacterial culture was used in PCR with LKR specific primers (400 bp). Two PCR reactions showed faint bands for LKR. Plasmids were prepared from $2 \mathrm{ml}$ of each positive culture, $1.5 \mathrm{ml}$ was used for a $12 \%$ glycerol stock and stored at $80^{\circ} \mathrm{C}$ and the remaining $1.5 \mathrm{ml}$ of culture was stored at $4^{\circ} \mathrm{C}$. Two $\mu \mathrm{l}$ of the prepared plasmid was used in a PCR with LKR specific primers (400 bp). A faint but positive PCR product was visible on the agarose gel. Therefore, the culture at $4^{\circ} \mathrm{C}$ was diluted $\left(1: 10^{2}, 1: 10^{4}, 1: 10^{6}\right)$ and plated to obtain individual colonies. To identify the single colony with LKR, $100 \mu 1$ of LB broth was dispensed into each well of a 96 well plate. Individual colonies were picked using a toothpick, then swirled in a well and allowed to grow for 5-6 hours. Two 
$\mu l$ from each culture was used as template in a PCR reaction. A total of three 96 well plates were used for the colony screen. No positive bands were observed on the agarose gel.

For the third screening, bacteria from the positive culture identified previously, as well as the library were plated. Positive areas were identified. Scrapings from the positive areas were grown for 5-6 hours in LB broth. Two $\mu$ l of the bacterial culture was used in PCR with LKR specific primers (400 bp). No positive bands were observed on the agarose gel.

To determine if LKR was present in the library, ten $1-\mu 1$ aliquots of library were used for template in ten PCR reactions. Two sets of primers were used. Set 1 forward and reverse primers anneal at the 1750 and 2003 nucleotide on mouse LKR cDNA to produce a 253 bp product. Set 2 forward and reverse primer anneal at the 1460 and 1750 nucleotide on mouse LKR cDNA to produce a 300 bp product. Set 1 confirmed the presence of LKR in the library, while the set 2 primers did not. The forward primer for set 2 is more $5^{\prime}$ on the LKR cDNA at 1460 than the forward primer for set 1 at 1750 , thus it is possible the library contains a partial LKR cDNA missing its 5' end. Moreover, the library may have more partial LKR cDNA clones than full length LKR clones hence, ten $\mu 1$ of library, which represents approximately 1000 plasmids, may not included a full length LKR cDNA clone.

LKR mRNA presumably represents $0.01 \%$ or less of the total mRNA population therefore, one would expect to screen at least half a million clones to identify LKR. Here less than 100,000 clones were screened, well below the predicted amount. The 
library screening was not time efficient due to the lack of growth on the plate, therefore two other strategies were attempted. 


\section{Results}

\section{5'Rapid Amplification of cDNA ends and chicken EST clone}

The first 5'RACE attempt yielded inner PCR products approximately 200bp and $600 \mathrm{bp}$ at an annealing temperature of $60^{\circ} \mathrm{C}$. To optimize the inner PCR conditions a temperature gradient for the annealing temperature was used however, the same two bands were predominant. The expected band size was around $1900 \mathrm{bp}$. Two $\mu \mathrm{l}$ of cDNA was used for template in a PCR with LKR specific primers. The PCR confirmed LKR was present in the cDNA population. However, it is possible that the 5' adaptors did not ligate to the mRNA ends. If so, then the forward primers could not anneal.

For the second 5'RACE procedure, mouse thymus RNA provided with the kit was used as a positive control for the CIP, TAP and ligation reaction. Primers for CXCR-4, a g-protein-coupled chemokine receptor, are provided in the kit and produce a $300 \mathrm{bp}$ product. The mouse control did yield the appropriate size PCR product for the nested PCR, thus the components of the kit are functioning properly.

Using cDNA from the second 5'RACE procedure, a temperature gradient $\left(60-65^{\circ} \mathrm{C}\right)$ for the annealing temperature was used for the outer PCR. The inner PCR annealing temperature was kept constant at $60^{\circ} \mathrm{C}$. The size of the nested products was dependent on the outer PCR annealing temperature. Inner PCR products yielded different size bands depending on which outer PCR products were used for template. A very faint band at $1000 \mathrm{bp}$ was detected from one inner PCR however, an attempt to T/A clone the band was unsuccessful. A temperature gradient $\left(55-65^{\circ} \mathrm{C}\right)$ for the nested PCR annealing temperature was used to optimize the PCR conditions, such that more product might be 
observed. For PCR template, the same outer PCR products that generated the $1000 \mathrm{bp}$ product were used. No PCR products were detected.

A second set of primers, which annealed at the 1848 and 1750 nucleotide sequence, and are more 5' of the first set of primers were used with cDNA generated from the second 5'RACE mRNA. Several optimization strategies were tried. Both random decamers and the LKR reverse primer were used for the reverse transcription. The following changes were tried for the outer PCR: 1) using twice the amount of primers or 2) twice as much cDNA. Temperature gradients were used for the inner PCR. The inner PCR, which used twice as much cDNA, revealed bands less than $400 \mathrm{bp}$. To confirm LKR is present in the cDNA, a PCR with the inner reverse (1750) or outer reverse primers (1848), respectively and a gene specific forward primer (1461) was executed. The cDNA made with both random primers and gene specific primers yielded the appropriate size bands. Thus, the inner and outer reverse primers find LKR in a normal PCR however, using the primer adaptor forward primers do not produce any large products. A 2-fold increase in the amount of RNA in the reverse transcription reaction did not improve the PCR results. Using twice as much outer PCR products for template in the inner PCR resulted in smearing. 


\section{Results}

\section{PCR approach for obtaining LKR from library}

5'LKR: Agarose gel analysis of the nested PCR revealed several bands for the 2003, 1848 combination of reverse primers. A predominant bright band at $1500 \mathrm{bp}$ and several faint bands at 1100, 1000, 900, 700, 450 and 200 basepairs, respectively. The smaller bands were assumed to represent LKR cDNA fragments missing the 5' end. The 1848, 1750 reverse primer combination produced only one band at $1500 \mathrm{bp}$. A $1500 \mathrm{bp}$ fragment from each primer combination was isolated and cloned. In retrospect, the other large bands (1100 and 1000) should have been cloned, as well. Plasmids from the clones were digested with Bst XI (New England Biolabs, Beverly, MA) and the products were separated on a $1 \%$ agarose gel. A 1500 bp band was observed. To confirm that the plasmids contain LKR, the plasmids were used for template in a PCR with LKR specific primers that anneal at the 1460 and 1750 nucleotide on mouse cDNA to produce a $300 \mathrm{bp}$ product. A $300 \mathrm{bp}$ product was observed for the plasmids. The plasmids were sequenced from both the M13 forward and reverse primer annealing sites. Analysis of the sequence using BLAST showed the clones did not contain LKR. Twelve nucleotides on the 3' end of the 1848 primer anneal to an E. coli gene. Interestingly, the sequence of LKR specific primers used to confirm the plasmids contained LKR were not in the E. coli sequence.

The 1848 primer was used in both primer combinations previously; therefore, for the second attempt, primer 2003 was used for the enrichment PCR and primer 1750 was used for the nested. Several faint bands were visible by gel analysis ranging in size from 3000 bp to $1000 \mathrm{bp}$. Five bands, sizes 3000, 2200, 2100, 1700 and $1000 \mathrm{bp}$, were cut out and cloned. Twenty-five colonies were PCR screened with LKR primers; briefly, white 
colonies were picked with a toothpick, touched to an LB plate and then swirled in PCR master mix. Five positive colonies ( 4 faint bands, 1 bright band) were identified, however, the PCR master mix showed evidence of contamination. The PCR was repeated and did not produce a PCR product.

3' LKR: Agarose gel analysis of the nested PCR products revealed several bands between $200 \mathrm{bp}$ and $1700 \mathrm{bp}$. Two faint bands at $1700 \mathrm{bp}$ were cut out of the gel and cloned. Only five positive colonies resulted from cloning. The plasmids were digested with Bst X I. Only one plasmid appeared to have an insert at 2000 bp. PCR with LKR specific primers and the plasmid did not produce a PCR product. A better approach for this method may have been to purify the plasmid prior to PCR. Bacterial culture and cellular components may have interfered with the PCR. 


\section{Discussion}

The objective of this study was two fold: 1) to identify the nucleotide sequence for chicken LKR and 2) obtain a clone containing LKR. The objectives were not accomplished however, the chances for success are more likely now. Recently, the LKR cDNA sequence was inferred from chicken genomic sequence and is available on the NCBI website. With this information, several new strategies for obtaining an LKR cDNA clone are possible.

First, the complete LKR cDNA could be amplified by PCR. Primers could be designed to the 5' and 3' ends. However, LKR is a large cDNA at 3.3kb making PCR amplification more difficult. Therefore, this procedure would require a special design and reagents. To ensure a full-length cDNA is transcribed and to prevent secondary structure formation, a highly processive reverse transcriptase which functions at higher temperatures may be necessary. cDNA from chicken liver RNA could be used as template. Moreover, it might be possible to PCR amplify LKR from the chicken plasmid library. Using isolated plasmids from the library might increase the PCR efficiency and decrease the chance for false positives.

Second, sections of LKR could be PCR amplified, cloned and ligated together. It would be possible then to have a bifuntional complete LKR/SDH clone and two clones containing the LKR domain or the SDH domain.

Third, the 5' and 3'RACE procedure could be attempted with new primers. The new primers could be more 5' and 3' therefore, the PCR products would be smaller $(>1000)$, which may increase the likelihood of success. A cDNA region which overlapped the 5' and 3' ends could be PCR amplified, cloned and ligated to the cDNA ends. 
Fourth, the cDNA plasmid library could be screened again provided more colonies grow on an individual plate. A longer probe could be designed which may eliminate false positives. 


\section{References}

1. Manangi, M., Hoewing, S.F.A., Engles, J.G., Higgins, A.D., Killefer, J., Wilson, M.E. and Blemings, K.P., 2004. Lysine a-ketoglutarate reductase is widely distributed in the chicken. Accepted to J.Nutr.

2. Sambrooke, J. and Russell, D.W., 2001. Molecular Cloning: A Laboratory Manual, $3^{\text {rd }}$ Ed., Cold Spring Harbor Press: Cold Spring Harbor, NY, p1.1321.142 .

3. Wang, S.H., Crosby, L.O. Nesheim, M.C., 1973. Effect of dietary excesses of lysine and arginine on the degradation of lysine by chicks. J. Nutr. 103, 384-391.

4. Zhu, X., Tang, G., Fabienne, G., Bouchez, D., Galili, G., 2001. A T-DNA insertion knockout of the bifunctional lysine-ketoglutarate reductase/saccharopine dehydrogenase gene elevates lysine levels in Arabidopsis seeds. Plant. Phys. 126, 1539-1545. 